\title{
The Effects of Background Zonal and Meridional Winds on ENSO in a Coupled GCM
}

\author{
BOWEN ZHAO \\ Yale University, New Haven, Connecticut \\ AleXey Fedorov \\ Department of Geology and Geophysics, Yale University, New Haven, Connecticut, and LOCEAN/IPSL, \\ Sorbonne University, Paris, France
}

(Manuscript received 4 December 2018, in final form 13 December 2019)

\begin{abstract}
Changes in background zonal wind in the tropical Pacific are often invoked to explain changes in ENSO properties. However, the sensitivity of ENSO to mean zonal winds has been thoroughly explored only in intermediate coupled models (following Zebiak and Cane), not in coupled GCMs. The role of mean meridional winds has received even less attention. Accordingly, the goal of this study is to examine systematically the effects of both zonal (equatorial) and meridional (cross-equatorial) background winds on ENSO using targeted experiments with a comprehensive climate model (CESM). Changes in the mean winds are generated by imposing heat flux forcing in two confined regions at a sufficient distance north and south of the equator. We find that the strengthening of either wind component reduces ENSO amplitude, especially eastern Pacific SST variability, and inhibits meridional swings of the intertropical convergence zone (ITCZ). The effect of zonal winds is generally stronger than that of meridional winds. A stability analysis reveals that the strengthening of zonal and meridional winds weakens the ENSO key positive feedbacks, specifically the zonal advection and thermocline feedbacks, which explains these changes. Zonal wind enhancement also intensifies mean upwelling and hence dynamical damping, leading to a further weakening of El Niño events. Ultimately, this study argues that the zonal and, to a lesser extent, meridional wind strengthening of the past decades may have contributed to the observed shift of El Niño characteristics after the year 2000.
\end{abstract}

\section{Introduction}

ENSO is the dominant mode of climate variability on interannual time scales-its warm phase El Niño and cold phase La Niña exert large impacts over the tropical Pacific and the entire globe (e.g., Philander 1990; Clarke 2008; Sarachik and Cane 2010). Thanks to continuing research efforts during the past several decades, the scientific community has achieved a growing understanding of ENSO mechanisms and significant skills in forecasting El Niño (e.g., Guilyardi et al. 2009, 2012; Fedorov and Brown 2009; McPhaden 2015; Hu and Fedorov 2016, 2017, 2018; Wang et al. 2017; Timmermann et al. 2018, and many other studies). Yet challenges persist: the current prediction skill for El Niño and La Niña remains rather limited and there is no clear consensus on how changes in the background tropical climatology can shape ENSO characteristics on decadal and longer time scales

Corresponding author: Bowen Zhao, bowen.zhao@yale.edu (e.g., Fedorov and Philander 2000; Collins et al. 2010; Cai et al. 2015).

Recent studies discuss two flavors of El Niño events as part of its broad continuum-the so-called eastern Pacific (EP) El Niño and central Pacific (CP) El Niño events, characterized by maximum sea surface temperature (SST) anomalies in the eastern tropical Pacific and the central tropical Pacific, respectively (Ashok et al. 2007; Fedorov et al. 2015; Kim and Yu 2012; Kug et al. 2009; Lee and McPhaden 2010; Lübbecke and McPhaden 2014; McPhaden 2012; McPhaden et al. 2011; Ren and Jin 2013). Remote impacts of CP El Niño are shown to be different from those of EP El Niño (Ashok and Yamagata 2009; Kim et al. 2011; Li et al. 2011). Whether EP and CP El Niño events can be both described by the rechargeoscillator theory (Jin 1997; Meinen and McPhaden 2000) is debated. Kug et al. $(2009,2010)$ concluded that the recharge/discharge mechanism is not active in $\mathrm{CP}$ events based on their observational analysis. However, Ren and Jin (2013) argued that removing contamination from 


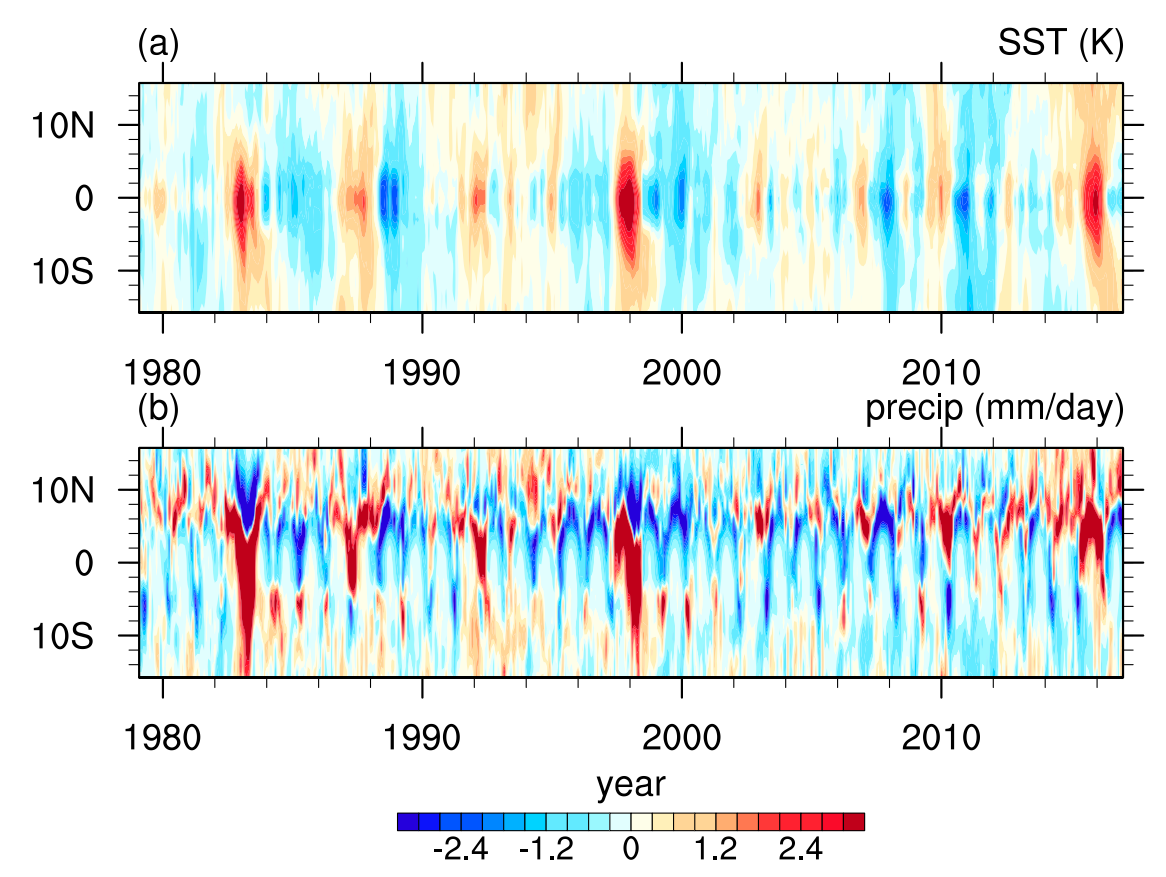

FIG. 1. Observed (a) SST and (b) precipitation anomalies averaged over the eastern tropical Pacific $\left(150^{\circ}-90^{\circ} \mathrm{W}\right)$ as a function of latitude and time; (a) and (b) share a common colorbar. Note in (b) that during El Niño events before the year 2000 the ITCZ, as marked by the precipitation maximum, typically migrated southward across the equator, but since then has remained in the Northern Hemisphere. Data are from the ERA-Interim reanalysis. Anomalies are computed with respect to the 1979-2014 climatology.

decadal variability does reveal the recharge/discharge process in both EP and CP events. Moreover, Fedorov et al. (2015) and $\mathrm{Hu}$ and Fedorov (2016) further demonstrated that the thermocline feedback operates in both types of El Niño.

The relative frequency of CP El Niño events has arguably increased since the end of the twentieth century (McPhaden et al. 2011). This recent transition toward generally weaker El Niño conditions contrasts the broadly discussed ENSO shift toward stronger El Niño events in the late 1970s (e.g., Fedorov and Philander 2000, 2001; Wang and An 2002; Guilyardi 2006) which manifested in a sequence of exceptionally strong warm events in the 1980s and 1990s. Following ENSO shifts, the interannual behavior of the ITCZ also changes: in the recent $\mathrm{CP}$-event dominated period, the cold tongue does not warm sufficiently during El Niño; consequently, the ITCZ has not crossed the equator since the year 2000 as was typical in the 1980s and 1990s. [Even in 2015 the ITCZ precipitation maximum stayed north of the equator; see Fig. 1; also see Hu and Fedorov (2018).] Whether the observed ENSO cycle shifts are related to anthropogenic warming (e.g., Yeh et al. 2009; McPhaden et al. 2011) or low-frequency internal climate variability such as the Atlantic multidecadal oscillation
(Dong et al. 2006; Zanchettin et al. 2016; Levine et al. 2017; Hu and Fedorov 2018) or merely happen at random (Wittenberg 2009; Wittenberg et al. 2014) is still debated.

The gradual strengthening of mean zonal winds has been suggested as one of the possible causes for the observed increase in the frequency of $\mathrm{CP}$ events during the past two decades (e.g., Yeh et al. 2009; Hu et al. 2013, 2017; Hu and Fedorov 2018). In fact, changes in mean easterly winds and mean ocean thermocline as part of changes in the background state of the tropical Pacific are often invoked as a potential mechanism for longterm modulations of the ENSO cycle (Fedorov and Philander 2000, 2001; Yeh et al. 2009; Collins et al. 2010). However, much of our understanding about mean state modulation of ENSO has been built on intermediate coupled models (e.g., Battisti and Hirst 1989; Fedorov and Philander 2000, 2001; Fedorov et al. 2003; Fedorov 2010; Wang and An 2002; Bejarano and Jin 2008; Ren and Jin 2013; Xie and Jin 2018) whereas few studies, to our knowledge, have examined the mean state-ENSO relation by conducting experiments with fully coupled GCMs (Dong and Sutton 2007).

Thus, the main goal of this study is to examine systematically the relation between the background state of 

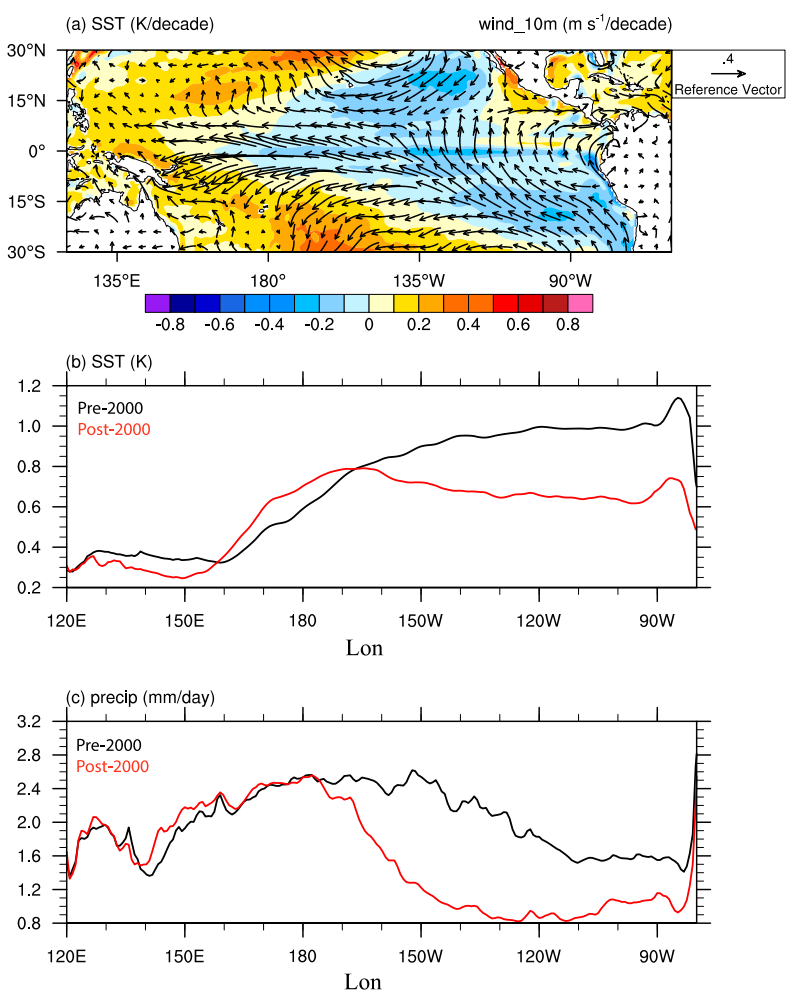

FIG. 2. (a) Observed trends in SST (colors; $\mathrm{K}$ decade ${ }^{-1}$ ) and surface winds (vectors; $\mathrm{m} \mathrm{s}^{-1}$ decade $^{-1}$ ) in the tropical Pacific from 1979 to 2014. Standard deviation of (b) SST and (c) precipitation anomalies along the equator for years 1979-2000 (black) and years 2000-14 (red). Note the strengthening of mean cross-equatorial winds in the eastern equatorial Pacific and of zonal winds in the western equatorial Pacific, the reduction in variance of the eastern Pacific SST and precipitation, and the shift of the variance maximum from the eastern to central equatorial Pacific. Data are from the ERA-Interim reanalysis.

the tropical Pacific and El Niño within a comprehensive, fully coupled climate model (CESM 1.2.2), focusing on the roles of mean equatorial zonal wind and crossequatorial meridional wind in modulating the ENSO cycle. This study is motivated in part by the observations of the tropical Pacific over the past several decades suggesting that from 1979 to 2014 zonal winds strengthened by roughly $30 \%$ (e.g., McPhaden et al. 2011; $\mathrm{Hu}$ et al. 2013; England et al. 2014; $\mathrm{Hu}$ and Fedorov 2016) and meridional winds strengthened by $40 \%-50 \%$ according to the ERA-Interim dataset (Fig. 2a; see also $\mathrm{Hu}$ and Fedorov 2018). This wind strengthening was paralleled by a shift in El Niño properties at the end of the twentieth century, reflected in the reduction of SST and precipitation variability in the equatorial eastern Pacific (Figs. 2b,c). Another motivation comes from the analyses of GCM biases showing that typical climate models have too strong zonal winds (Burls et al. 2017) but too weak cross-equatorial winds (Hu and Fedorov 2018). How such wind changes and model biases can affect El Niño is the main question of this study.

While equatorial zonal winds have been long considered an important factor controlling ENSO properties (e.g., Fedorov and Philander 2000, 2001; Fedorov 2010; Xie and Jin 2018), we rationalize our consideration of mean cross-equatorial winds as follows. Some future climate projections (Xie et al. 2010; He and Soden 2015) suggest a north-south dipole-like change across the equator in the eastern Pacific SST warming pattern (both the northeastern and southeastern subtropical Pacific become warmer but the northern regions warm more), which should result in a strengthening of crossequatorial winds. Figure 2a hints to such a dipole-like structure in the observed SST trends-the cooling of the southeastern subtropical Pacific and a slight warming north of the equator extending from the Caribbean Sea, which favors stronger meridional winds. In addition, recent studies of the Pacific meridional modes (PMM) have proposed a mechanism of subtropical SST anomalies influencing equatorial ENSO dynamics via the wind-evaporation-SST (WES) feedback (Chang et al. 2007; Zhang et al. 2014; Di Lorenzo et al. 2015). Further, several studies of the failed $2014 \mathrm{El} \mathrm{Niño} \mathrm{discuss} \mathrm{a} \mathrm{role}$ for strong cross-equatorial (meridional) wind anomalies in impeding the expected El Niño evolution during that year (Min et al. 2015; Zhu et al. 2016; Wu et al. 2018). While the latter example occurs on intraseasonal time scales, eastern subtropical Pacific SST anomalies and the associated cross-equatorial winds could also play a role in the low-frequency modulation of the ENSO cycle. To summarize, our study allows us to compare and contrast the respective roles of background zonal and meridional winds in ENSO dynamics.

This paper is organized as follows. Section 2 gives a brief introduction to the coupled model used and the experimental setup. The results from the numerical experiments and diagnostics of relevant mechanisms are presented in section 3. A summary and brief discussion are given in section 4 .

\section{Model setup and experimental approach: Imposing mean state changes}

Numerical experiments in this study are conducted with the fully coupled Community Earth System Model (CESM 1.2.2) with CAM5 physics (Hurrell et al. 2013) developed at the National Center for Atmospheric Research (NCAR). The model is run with a horizontal resolution of approximately $2^{\circ}$ for the atmospheric and land components, and approximately $1^{\circ}$ for the ocean and ice components (the ocean resolution becomes 

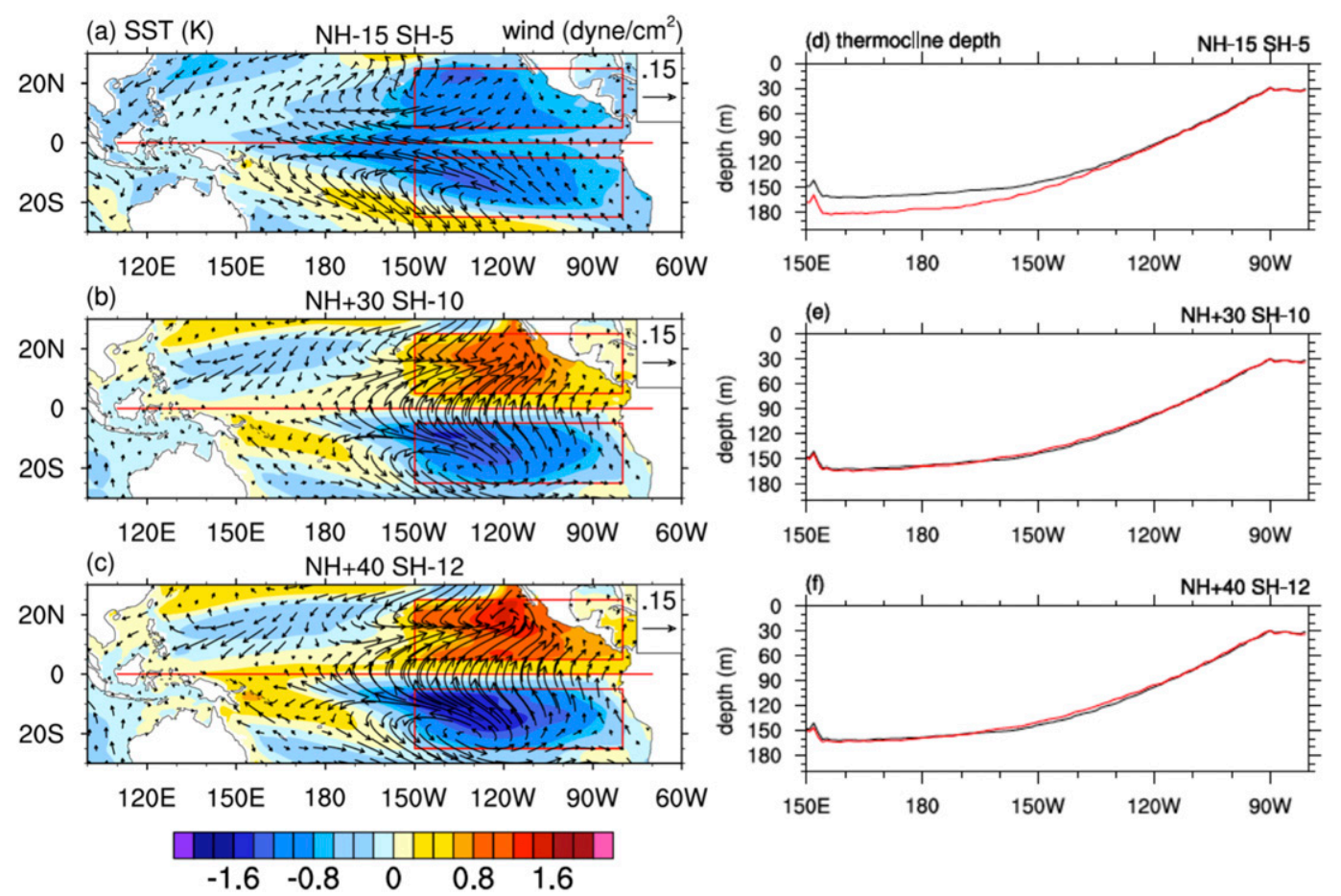

FIG. 3. Perturbing the mean state of the tropical Pacific. (a)-(c) Induced mean SST (colors; K) and wind stress (vectors; dyne $\mathrm{cm}^{-2}$ ) changes in the perturbation experiments relative to the control. Surface heat flux perturbations have been added in the marked boxes in the eastern Pacific north and south of the equator. The magnitudes and signs of the imposed perturbations are indicated in the names of the experiments (see text for further details). The perturbations are designed to induce zonal [in (a)] or meridional [in (b) and (c)] mean wind changes. (d)-(f) Mean thermocline depth for the control (black) and perturbed runs (red) introduced in the left column. Note that in the $\mathrm{NH}-15 / \mathrm{SH}-5$ experiment the thermocline deepens in the central/western tropical Pacific due to the strengthened easterly winds while in the $\mathrm{NH}+30 / \mathrm{SH}-10$ and $\mathrm{NH}+40 / \mathrm{SH}-12$ experiments the thermocline slope is not affected as zonal winds barely change.

successively finer in the vicinity of the equator, reaching roughly $0.3^{\circ}$ of latitude at the equator). The atmosphere has 30 vertical levels while the ocean has 60 vertical levels, with 20 levels concentrated within the top $200 \mathrm{~m}$. All runs use preindustrial (the year 1850) radiative and boundary conditions before the heat flux perturbations are added.

To generate changes in mean equatorial winds, we add localized anomalies in surface heat fluxes to the ocean component of the coupled model. These surface flux perturbations are imposed over two regions of the northeastern and southeastern tropical/subtropical Pacific on both sides of the equator $\left(150^{\circ}-80^{\circ} \mathrm{W}, 5^{\circ}-25^{\circ} \mathrm{N}\right.$, and $25^{\circ}-$ $5^{\circ} \mathrm{S}$, shown as boxes in Fig. 3). Additional sensitivity experiments with surface heat flux perturbation imposed over the $10^{\circ}-30^{\circ} \mathrm{N}$ and $10^{\circ}-30^{\circ} \mathrm{S}$ latitudinal bands, located farther from the equator, yield similar results (not shown), so it appears that the imposed perturbation fluxes do not directly affect equatorial ocean dynamics important for ENSO. We also refer the readers to the study of $\mathrm{Hu}$ and Fedorov (2018), who superimposed anomalous cross-equatorial wind stress forcing onto the modelgenerated wind stress. While that study yielded generally similar conclusions as our study, our approach of inducing wind anomalies is more physical as it does not affect ocean-atmosphere coupling.

To strengthen mean zonal winds, we add negative heat flux perturbations to both regions; the same-sign perturbations imposed on each side of the equator reinforce changes in zonal winds but minimize any changes in meridional winds (Fig. 3a). The result is roughly analogous to imposing a linear combination of the North Pacific and South Pacific meridional mode patterns of the same sign: while the imposed northern cold SST anomalies tend to induce enhanced northeasterly trade wind, the southern cold anomalies tend to induce enhanced southeasterly trade winds; their zonal components add constructively but their meridional components cancel each other. For example, in the experiment denoted NH-15/SH-5 we superimpose a constant heat flux of roughly $-15 \mathrm{~W} \mathrm{~m}^{2}$ in the box north of the equator and $-5 \mathrm{~W} \mathrm{~m}^{2}$ in the box south of the equator. It turns out 
that we consistently need the Northern Hemisphere $(\mathrm{NH})$ perturbation heat flux to be about 3 times stronger than the Southern Hemisphere (SH) heat flux to keep meridional winds unchanged (see a detailed discussion below). In response to the stronger zonal winds, the equatorial thermocline steepens as expected (Fig. 3d).

Next, to strengthen meridional (cross-equatorial) winds, we add a positive heat flux of about $30 \mathrm{~W} \mathrm{~m}^{2}$ to the northern box, and a negative heat flux of $\sim-10 \mathrm{~W} \mathrm{~m}^{2}$ to the southern box (Fig. 3b; experiment denoted as $\mathrm{NH}+30 / \mathrm{SH}-10)$. The effect of such opposing heat flux perturbations on both sides of the equator is to reinforce changes in mean meridional winds but minimize changes in zonal winds. This result of such a forcing could be understood as imposing the North Pacific and South Pacific meridional mode patterns of opposite signs; the ocean response is also similar to a shallow-water model solution with asymmetric thermal forcing (Fig. 2 in Gill 1980). Further, the readers could draw an analogy with the South Asian monsoon, wherein cross-equatorial winds change direction seasonally following the interhemispheric thermal gradient. Consistent with small zonal wind changes, the equatorial thermocline remains largely unaffected (Fig. 3e). In our third experiments, we strengthen the opposing heat flux forcing on both sides of the equator by about $20 \%$ (Figs. 3c and 3f; the $\mathrm{NH}+40 / \mathrm{SH}-12$ experiment) in order to demonstrate the robustness of our results for meridional wind modifications.

As mentioned above, to modify mean winds we impose NH heat flux perturbations about 3 times stronger than SH heat flux perturbations, which ensures an approximate cancellation of either zonal or meridional wind changes, depending on the chosen sign of the flux perturbation in each hemisphere. This is because ocean response to the imposed heat flux perturbations involves two feedbacks: a negative SST-latent heat flux feedback and a positive wind-evaporation-SST (WES) feedback. However, the positive WES feedback is much stronger south of the equator due to stronger trade winds there while the negative SST-latent heat flux feedback is much stronger north of the equator due to the warmer background SSTs. Thus, we need a stronger heat flux perturbation north of the equator, which ultimately results from the north-south asymmetry in the eastern tropical Pacific climatology. On the other hand, the shortwave and longwave radiation response, if normalized by the magnitude of SST anomalies, is very similar in both regions, indicating similar cloud/convection response (not shown).

\section{Changes in the annual mean climatology}

The induced changes in the annual mean equatorial wind stress and subsurface temperature are summarized in Fig. 4. As mentioned above, in the NH-15/SH-5 experiment equatorial zonal wind strengthens significantly (by $\sim 30 \%$, similar to the observed changes during 1979-2014; see above), while meridional wind remains the same. In this experiment the equatorial ocean cools by $\sim 1^{\circ} \mathrm{C}$ in the top $100 \mathrm{~m}$ due to the combined influence from enhanced evaporation, upwelling and zonal advection but warms at depth in the west by up to $2^{\circ} \mathrm{C}$ due to the thermocline deepening.

We note here that the equatorial thermocline responds to zonal wind strengthening on decadal and longer time scales differently than on ENSO time scales (e.g., Fedorov 2010). Specifically, changes in the thermocline slope on ENSO time scales typically involve deepening in the west and shoaling in the east; in contrast, persistent/slow zonal wind strengthening increases the tilt but also increases basinwide ocean heat content along the equator, so that the deepening of the mean thermocline partially or completely compensates the thermocline shoaling in the east (as seen in the NH-15/SH-5 case). In the NH+30/SH-10 and $\mathrm{NH}+40 / \mathrm{SH}-12$ simulations, annual mean equatorial zonal wind stress strengthens slightly in the west but weakens in the east, so that the zonal mean remains largely unchanged. These small residual wind stress anomalies propagate westward over the course of the year, possibly contributing to the interesting subsurface temperature pattern evident in Figs. $4 \mathrm{~h}$ and $4 \mathrm{j}$ through the fast, local dynamical balance between the thermocline slope and equatorial zonal wind stress, that is, $(\partial h / \partial x) \propto \tau_{x}$ where $h$ and $\tau_{x}$ denote anomalies in thermocline depth and zonal wind stress.

Meanwhile, annual mean cross-equatorial winds strengthen in the $\mathrm{NH}+30 / \mathrm{SH}-10$ and $\mathrm{NH}+40 / \mathrm{SH}-12$ runs (the meridional wind strength increases by about $80 \%$ in the former and almost doubles in the latter, which is nominally greater than the observed $50 \%$ change during 1979-2014, see above; however, one should keep in mind that mean cross-equatorial winds simulated by the model in the Control experiment are actually weaker than the observed). As zonal mean zonal wind stress does not change much, the equatorial SSTs do not change much in these two runs. However, the equatorial ocean warms significantly below the thermocline while it cools in the east just above the thermocline. Thus the eastern equatorial Pacific exhibits a weaker stratification around the thermocline, which could potentially weaken the (positive) thermocline feedback (Fedorov and Philander 2001). The cause of these temperature anomalies will be discussed in detail below. To summarize, the mean state changes in the zonal and meridional wind perturbation experiments are very different, consistent with the fact that zonal wind strengthening dominates in the first experiment while meridional wind strengthening dominates in the second two.

Also note that in all three perturbed runs, there is no clear increase or decrease in the equatorial SST zonal 


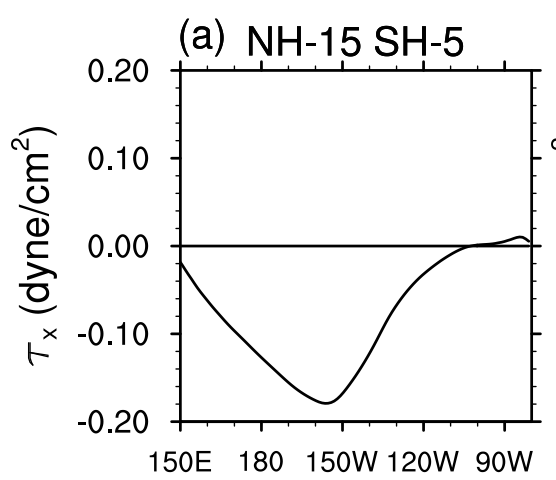

(d)
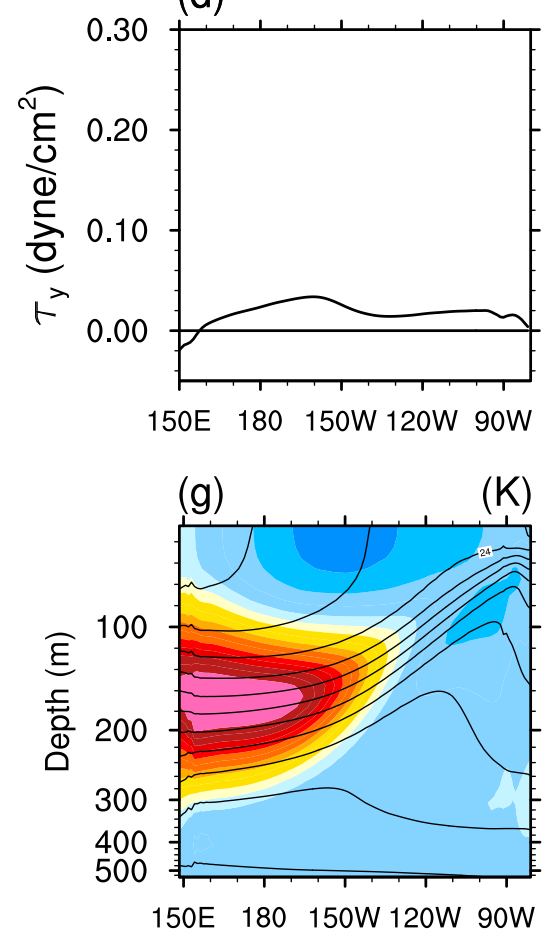

(b) $\mathrm{NH}+30 \mathrm{SH}-10$

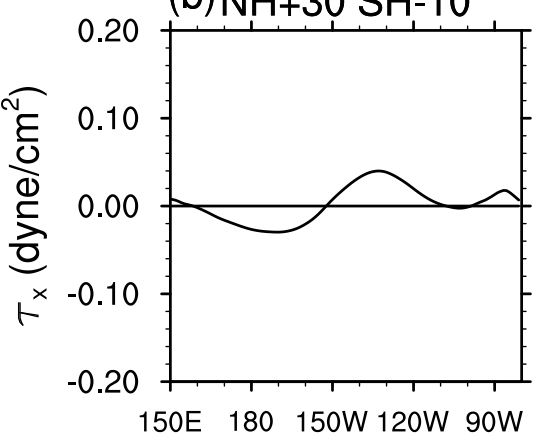

(e)
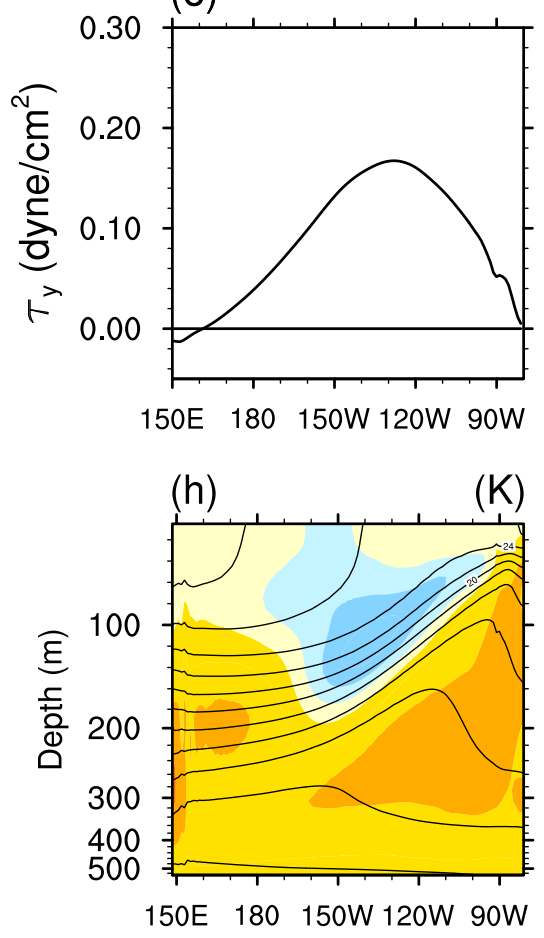

(c) $\mathrm{NH}+40 \mathrm{SH}-12$

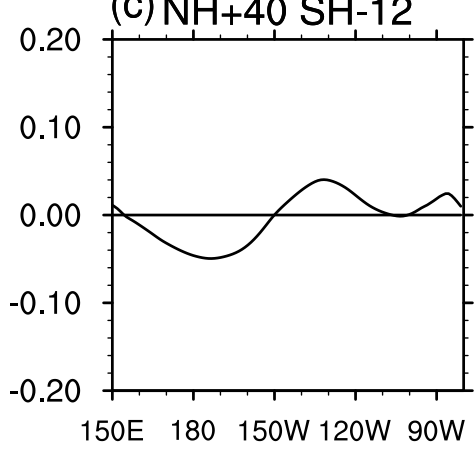

(f)
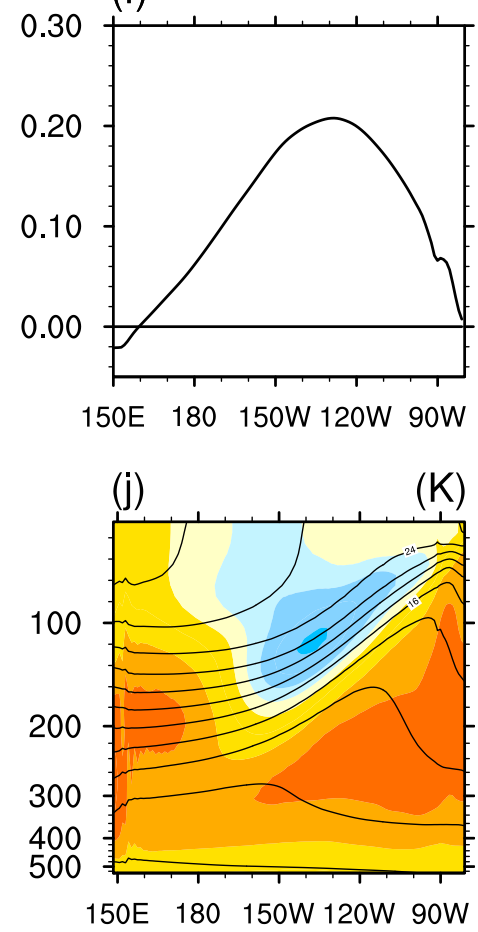

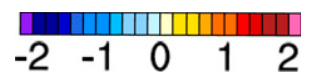

FIG. 4. Mean changes along the equator (averaged in the band $5^{\circ} \mathrm{S}-5^{\circ} \mathrm{N}$ ) induced in the perturbation experiments for (a)-(c) mean zonal and (d)-(f) meridional wind stress, and for (g)-(j) ocean subsurface temperature. Mean isotherms from the control experiment are also shown in the bottom row. (left) $\mathrm{NH}-15 / \mathrm{SH}-5$, (middle) $\mathrm{NH}+30 / \mathrm{SH}-10$, and (right) $\mathrm{NH}+40 / \mathrm{SH}-12$ experiments, respectively. Note that zonal wind stress changes substantially in the $\mathrm{NH}-15 / \mathrm{SH}-5$ run but only little in the $\mathrm{NH}+30 / \mathrm{SH}-10$ and $\mathrm{NH}+40 / \mathrm{SH}-12$ runs. Also note the increase in meridional wind stress in the $\mathrm{NH}+40 / \mathrm{SH}-12$ run, corresponding to a stronger forcing in this run.

gradient. In the case of perturbed zonal winds this could indicate that the tropical mean state is in a "saturated" regime such that the strengthening of mean zonal winds does not affect the zonal SST gradient (Liu and Huang 1997; Burls and Fedorov 2014; Fedorov et al. 2015). However, since this model suffers from the too cold cold tongue and too strong easterly wind biases relative to the observations, as many other coupled models do (Hurrell et al. 2013; Li and Xie 2014), whether this "saturation" regime is applicable to the present-day ocean remains to be seen.

\section{Results: Changes to the ENSO cycle}

\section{a. Simulated changes in ENSO}

In this section, we examine changes in the ENSO cycle in response to our imposed heat flux forcing and the resultant changes in wind stress. We first focus on the 

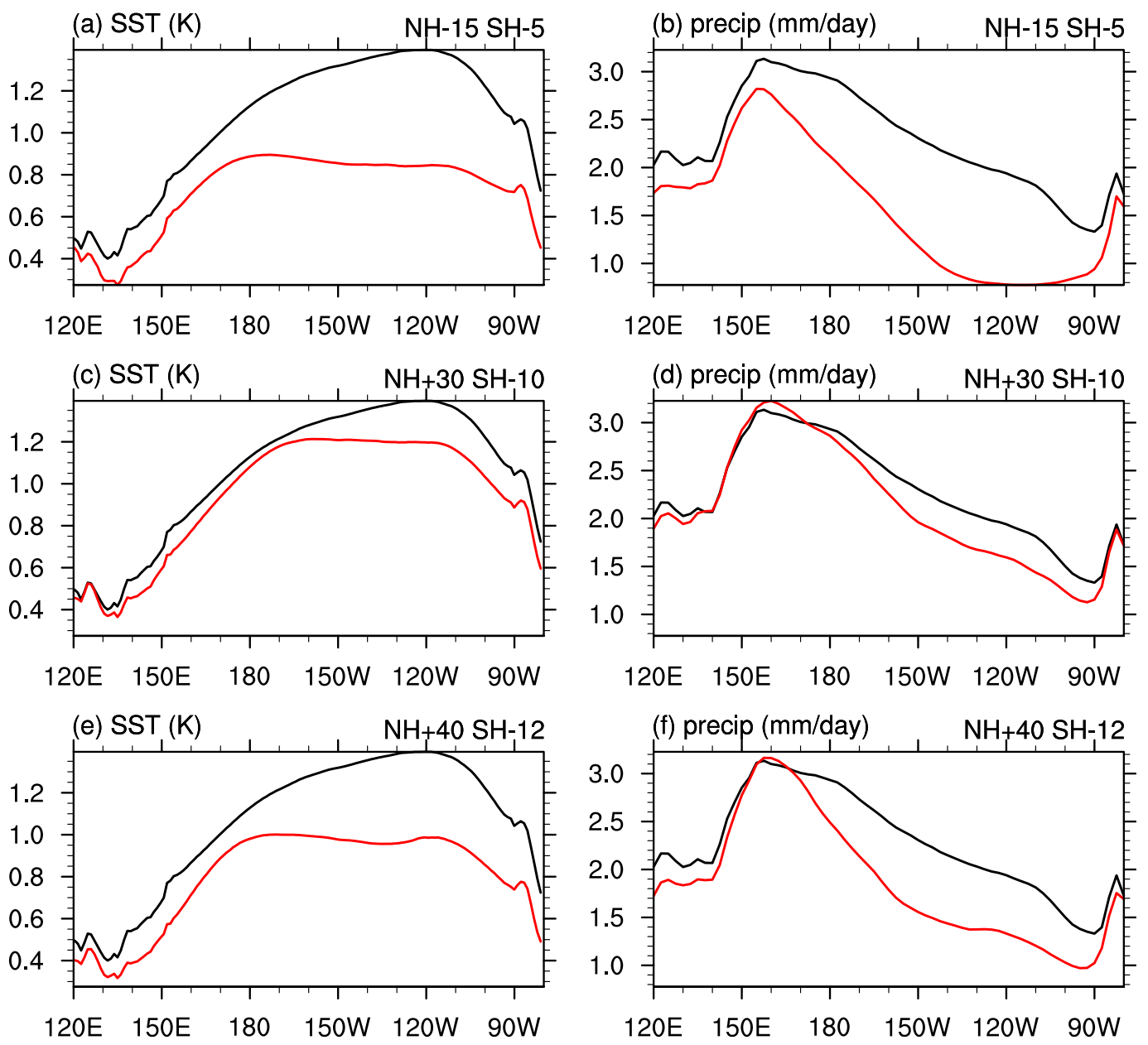

FIG. 5. Standard deviation for (a),(c),(e) SST anomalies and (b),(d),(f) precipitation anomalies along the equator for the control (black) and perturbation (red) experiments. Note the reduction in standard deviation in the eastern equatorial Pacific and the general weakening of the ENSO signal in the perturbed runs, indicating a shift from stronger EP events to weaker CP events, analogous to the observations (cf. Fig. 1). Thus, background crossequatorial meridional winds play a similar role as background equatorial zonal winds in changing the ENSO cycle characteristics.

GCM results and later investigate the causes of the simulated ENSO changes using the Bjerknes stability index (Jin et al. 2006).

The Niño-3 standard deviation decreases from $1.28^{\circ} \mathrm{C}$ in the control run to about $0.79^{\circ}, 1.11^{\circ}$, and $0.90^{\circ} \mathrm{C}$ in the three perturbed runs, respectively. Variability in both SST and precipitation is reduced especially east of the date line (Fig. 5), which is similar to the observations of the past two decades (Fig. 2).

As we mentioned earlier, the reduction in eastern Pacific SST anomalies during recently observed El Niño events has been accompanied by changes in the ITCZ behavior-the ITCZ is less likely now to cross the equator during warm events (Fig. 1). This relation also holds in our numerical experiments. While SST anomalies remain meridionally symmetric with respect to the equator in the perturbed runs (not shown), the ITCZ movements are more confined to the $\mathrm{NH}$ in the perturbed runs (Fig. 6): the frequency of the ITCZ crossing the equator decreases from $\sim 8$ per century in the control run to essentially no crossing in the NH-15/SH-5 run and to about 2 to 3 crossings per century in the $\mathrm{NH}+30 / \mathrm{SH}-10$ and $\mathrm{NH}+40 / \mathrm{SH}-12$ runs.

The similarity between the simulated ENSO changes in the perturbation experiments and the observed changes since the year 2000 suggests that the observed strengthening of zonal as well as cross-equatorial winds could have been responsible for the ENSO cycle shifts around year 2000. Note that our induced zonal wind change in the $\mathrm{NH}-15 / \mathrm{SH}-5$ run is approximately of the same magnitude as the observed zonal wind change while the imposed meridional wind change in $\mathrm{NH}+40$ / 
(a) control precip

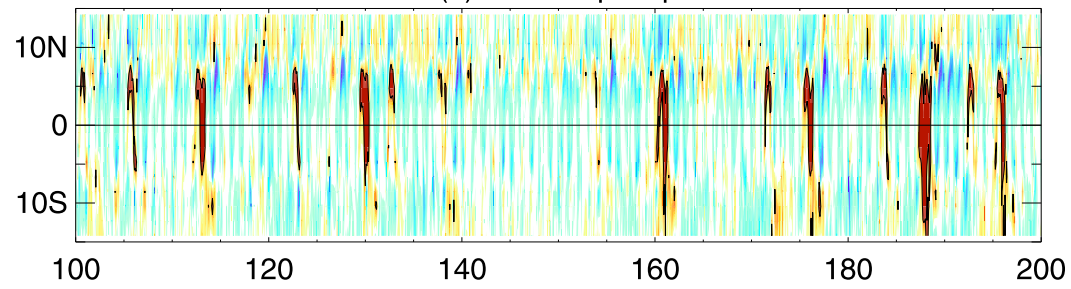

(b) $\mathrm{NH}-15 \mathrm{SH}-5$ precip

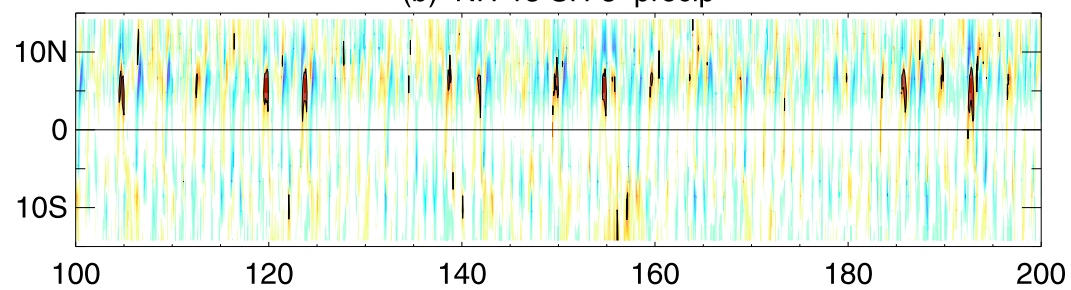

(c) $\mathrm{SH}-10 \mathrm{NH}+30$ precip

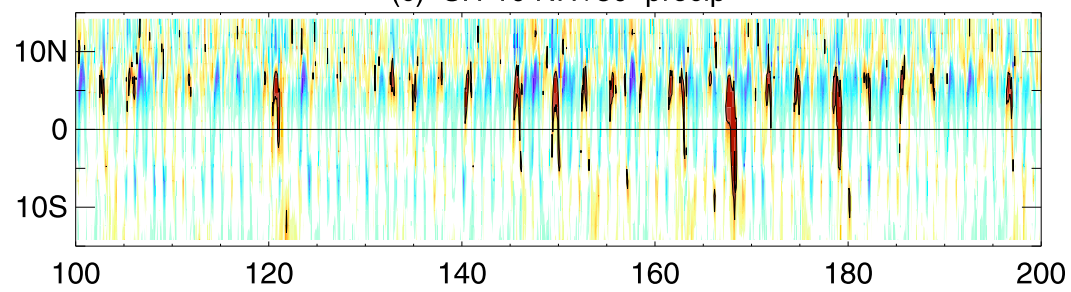

(d) $\mathrm{SH}-12 \mathrm{NH}+40$ precip

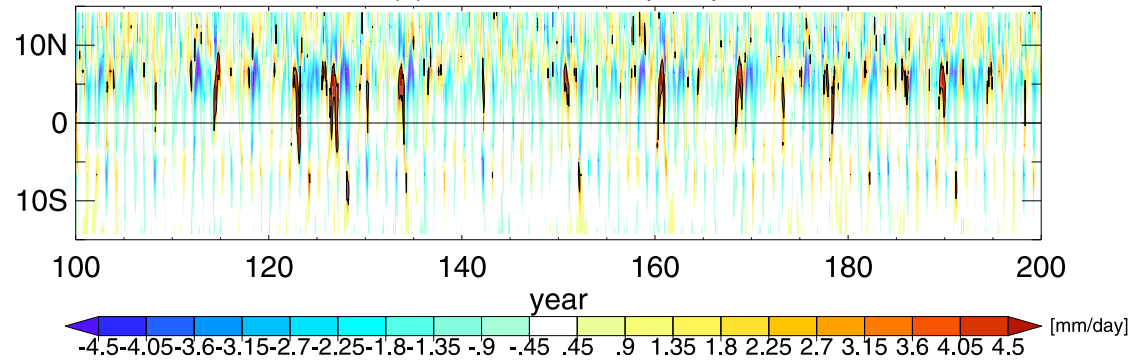

FIG. 6. Precipitation anomalies averaged over the eastern tropical Pacific $\left(150^{\circ}-90^{\circ} \mathrm{W}\right)$ as a function of latitude and time, for (a) the control run and (b)-(d) the perturbation experiments. Only model years 1000 to 2000 are shown for clarity. Whereas SST anomalies in the perturbed runs are still nearly symmetric with respect to the equator (not shown), precipitation anomalies are now more confined to the Northern Hemisphere due to the imposed forcing and the shift in El Niño characteristics.

$\mathrm{SH}-12$ run is almost double the observed value based on the trend for 1979-2014. This suggests that in nature the effect of the meridional wind strengthening on ENSO might be generally weaker, though still important, than the contribution from the zonal wind strengthening.

\section{b. Analyzing the key mechanisms: The Bjerknes stability index}

Within the recharge-discharge oscillator framework, Jin et al. (2006) proposed to use a stability index to quantify the net strength of major feedbacks affecting
SST in the eastern/central equatorial Pacific as part of the ENSO cycle. This index, referred to as the Bjerknes stability index $\left(I_{\mathrm{BJ}}\right)$, has been employed to explain changes in ENSO cycles in both observations (Lübbecke and McPhaden 2013, 2014) and GCMs (Kim and Jin 2011b; Manucharyan and Fedorov 2014). Here we use the Bjerknes index to diagnose the causes of weaker eastern Pacific SST anomalies in the perturbed runs, corresponding to the shift of the dominant El Niño "flavor" from EP to CP. The $I_{\mathrm{BJ}}$ index definition in this study closely follows the notations of Manucharyan and Fedorov (2014), 
TABLE 1. Definitions of key parameters used in the computation of the Bjerknes index $I_{\mathrm{BJ}}$. We use angle brackets to indicate taking a volume average from the ocean surface to the base of the mixed layer over the Niño-3 region; we also use square brackets to indicate taking a volume average over the entire equatorial Pacific $\left(150^{\circ} \mathrm{E}-90^{\circ} \mathrm{W}\right)$, not just the Niño-3 region.

\begin{tabular}{cc}
\hline \hline Parameter & Definition \\
\hline$\mu_{a}$ & {$\left[\tau_{x}^{\prime}\right]=\mu_{a}\left\langle T^{\prime}\right\rangle$} \\
$\beta_{u}$ & $\left\langle u^{\prime}\right\rangle=\beta_{u}\left[\tau_{x}^{\prime}\right]$ \\
$\beta_{w}$ & $\left\langle\mathscr{H}(\bar{w}) w^{\prime}\right\rangle=-\beta_{w}\left[\tau_{x}^{\prime}\right]$ \\
$\beta_{h}$ & $\left\langle h^{\prime}\right\rangle=\beta_{h}\left[\tau_{x}^{\prime}\right]$ \\
$a_{h}$ & $\left\langle\mathscr{H}(\bar{w}) T_{50 \mathrm{~m}}^{\prime}\right\rangle=a_{h}\left\langle h^{\prime}\right\rangle$ \\
$\alpha_{s}$ & $Q_{s}=-\alpha_{s}\left\langle T^{\prime}\right\rangle$ \\
\hline
\end{tabular}

$$
\begin{aligned}
2 I_{\mathrm{BJ}}= & -\alpha_{s}-\frac{\langle\bar{u}\rangle}{L_{x}}-\frac{\langle-2 y \bar{v}\rangle}{L_{y}^{2}}-\frac{\langle\mathscr{H}(\bar{w}) \bar{w}\rangle}{H_{m}}+\mu_{a} \beta_{u}\left\langle\frac{\partial \bar{T}}{\partial x}\right\rangle \\
& +\mu_{a} \beta_{w}\left\langle\frac{\partial \bar{T}}{\partial z}\right\rangle+\mu_{a} \beta_{h} a_{h}\left\langle\frac{\bar{w}}{H_{m}}\right\rangle-\varepsilon,
\end{aligned}
$$

where $T$ denotes SST, $\tau_{x}$ is zonal wind stress, $h$ is thermocline depth, and $u, v$, and $w$ are the zonal, meridional, and vertical velocity components, respectively. Overbars denote climatological time mean values; angle brackets indicate taking a volume average from the ocean surface to the base of the mixed layer over the Niño-3 region; when defining some of the equation parameters (Table 1), we also use square brackets to indicate taking a volume average over the entire equatorial Pacific $\left(150^{\circ} \mathrm{E}-90^{\circ} \mathrm{W}\right)$, not just the Niño-3 region. We also use primes to indicate anomalies relative to timemean values. The length scales $L_{x}$ and $L_{y}$ give the zonal and meridional extent of the averaging region while $H_{m}$ represents the mixed layer depth $(50 \mathrm{~m})$. Our conclusions remain qualitatively similar if we modify the zonal or meridional extent of volume averaging. We refer the reader to Jin et al. (2006), Kim and Jin (2011a), and Manucharyan and Fedorov (2014) for further details.

Parameters $\alpha_{s}, \mu_{a}, \beta_{u}, \beta_{w}, \beta_{h}$, and $a_{h}$ are sensitivity parameters estimated from the observations using a least squares linear regression method (Table 1). Parameter $\alpha_{s}$ describes the SST thermal damping strength; $\mu_{a}$ describes the basinwide zonal wind stress response to eastern Pacific SST anomalies; $\beta_{u}, \beta_{w}$, and $\beta_{h}$ describe the response of eastern Pacific zonal current, upwelling, and thermocline depth, respectively, to equatorial zonal wind stress anomalies; $a_{h}$ describes the subsurface $(50 \mathrm{~m})$ temperature response to thermocline movement, which depends on ocean stratification around the thermocline.

Accordingly, the terms on the right-hand side of Eq. (1) represent thermal damping, dynamical damping by mean zonal and meridional currents and by mean upwelling, and the zonal advection, Ekman, and thermocline feedbacks. The last term arises from the coupling between eastern Pacific SST and western Pacific thermocline depth (Jin 1997; Kim and Jin 2011a), where $\varepsilon$ is the oceanic damping rate of western Pacific thermocline anomalies. This term is small and remains fairly constant across different experiments, and as such is omitted from the analysis.

For the control run, we obtain a slightly positive stability index $\left(\sim 0.1 \mathrm{yr}^{-1}\right)$, consistent with the notion that the ENSO cycle is close to being neutrally stable in the observations and in many GCMs (Fedorov and Philander 2000; Kim and Jin 2011b). The magnitudes of all terms contributing to $I_{\mathrm{BJ}}$, except for the $\varepsilon$ term, are shown for the control run in Fig. 7a. As expected, in the control run the damping term is dominated by the mean upwelling dynamical damping $\left(W_{\text {damp }}\right)$, followed by the thermal damping. The zonal advection and thermocline feedbacks contribute to the growth of temperature anomalies the most while the Ekman feedback contributes much less.

Note that advection by mean meridional current of anomalous temperature $\left(V_{\text {damp }}\right)$ makes a nontrivial positive contribution to the growth of eastern Pacific SST anomalies, consistent with what $\mathrm{Hu}$ et al. (2016) found in an ocean reanalysis (Global Ocean Data Assimilation System). This positive contribution comes from the fact that the mean poleward meridional velocity (due to Ekman divergence) in the model acts to broaden SST anomalies, creating a positive contribution to SST anomalies when averaged over the Niño-3 region $\left(5^{\circ} \mathrm{S}-5^{\circ} \mathrm{N}\right)$. This positive contribution is different from conventional positive feedbacks in the sense that by itself it cannot not maintain SST anomaly growth but it can however contribute to positive feedbacks by warming SST and weakening the trade winds.

The stability index $I_{\mathrm{BJ}}$ becomes negative for all perturbed runs: its magnitude is approximately $-0.64 \mathrm{yr}^{-1}$ in the NH-15/SH-5 run, $-0.4 \mathrm{yr}^{-1}$ in the $\mathrm{NH}+30 / \mathrm{SH}-10$ run, and $-0.62 \mathrm{yr}^{-1}$ for the $\mathrm{NH}+40 / \mathrm{SH}-12$ run. The corresponding changes in the stability indices and their contributions from different terms in the perturbed experiments relative to the control are shown in Figs. 7b-d.

\section{c. Changes in damping terms}

Let us first examine the $\mathrm{NH}-15 / \mathrm{SH}-5$ run (i.e., changing mean zonal winds). The thermal damping (the HF term) weakens as a result of mean SST cooling, which implies a weaker negative latent heat feedback (due to the exponential dependence of latent heat flux on SST stemming from the Clausius-Clapeyron relation) as well as a more positive low cloud feedback (more low clouds) in the eastern tropical Pacific. The 
(a) control

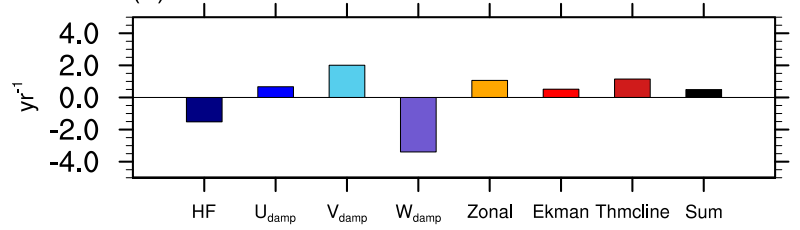

(b) $\mathrm{NH}-15 \mathrm{SH}-5$ minus control

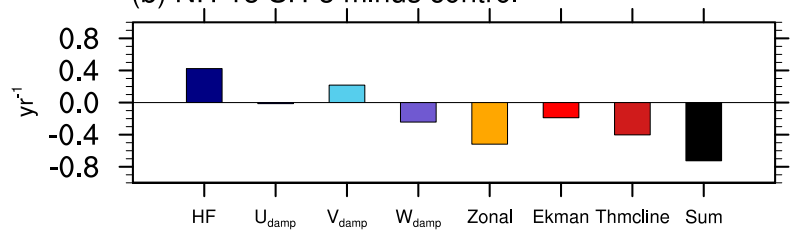

(c) $\mathrm{NH}+30 \mathrm{SH}-10$ minus control

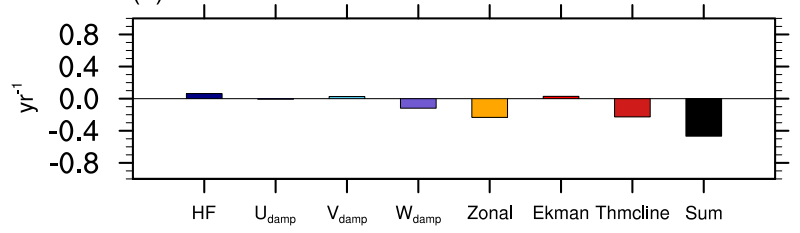

(d) $\mathrm{NH}+40 \mathrm{SH}-12$ minus control

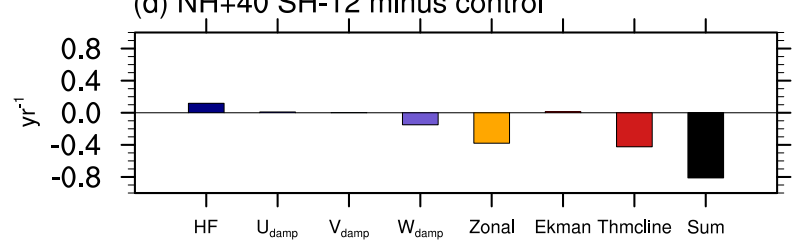

FIG. 7. Different terms contributing to the Bjerknes stability index $I_{\mathrm{BJ}}$. (from left to right) Thermal damping (HF), damping by mean zonal current $\left(U_{\text {damp }}\right)$, damping by mean meridional current $\left(V_{\text {damp }}\right)$, damping by mean upwelling $\left(W_{\text {damp }}\right)$, zonal advection feedback (zonal), Ekman feedback (Ekman), thermocline feedback (Thmcline), and the sum of all these terms. Values shown are (a) for the control run and (b)-(d) the differences between each perturbed run and the control run. Note the reduction in the zonal advection (zonal) and thermocline (Thmcline) feedbacks contributes most to the reduction in $I_{\mathrm{BJ}}$ in the $\mathrm{NH}+30 / \mathrm{SH}-10$ and $\mathrm{NH}+40 /$ $\mathrm{SH}-12$ runs, in (c) and (d) respectively. Note that the sum is different from $I_{\mathrm{BJ}}$ by a factor of 2 (see text). The term $\varepsilon$ in Eq. (1) is neglected.

term due to anomalous advection by the mean meridional current $\left(V_{\text {damp }}\right)$ is more positive while the damping by mean upwelling is more negative in this run. This partial cancellation is due to the enhancement of both the mean meridional current and mean upwelling as a response to the trade wind strengthening. In fact, the oceanic subtropical cells (STCs) become stronger. Thus, total damping (thermal damping plus dynamical damping) actually weakens and hence cannot explain the weakening of eastern Pacific El Niño SST anomalies; the weakening of El Niño anomalies is then necessarily a result of weaker positive feedbacks.

Next, let us look at the damping term changes in the two meridional wind experiments, the $\mathrm{NH}+30 / \mathrm{SH}-10$ and $\mathrm{NH}+40 / \mathrm{SH}-12$ runs. Whereas all major positive feedback terms become weaker again, the mean damping terms remain relatively unchanged. The different responses of the damping terms between the two meridional wind experiments and the zonal wind experiment arise from different mean state changes. As mentioned in section 2, the equatorial SST changes very little in the two meridional wind experiments as their mean zonal wind stress is almost unaffected, which explains the weak change in the thermal damping strength (the HF term).

Changes in the mean currents in the meridional experiments are also different from those in the zonal wind experiment. In the NH-15/SH-5 run, both the $\mathrm{NH}$ and SH subtropical cells strengthen, corresponding to a net strengthening in mean equatorial upwelling and Ekman divergence when averaged over $5^{\circ} \mathrm{S}-5^{\circ} \mathrm{N}$ (not shown). However, in the two meridional wind experiments, the mean upwelling and mean Ekman divergence, again averaged over $5^{\circ} \mathrm{S}-5^{\circ} \mathrm{N}$, remain largely unchanged due to the cancellation between these effects north and south of the equator. As shown in Fig. 8a, the induced wind stress curl change is roughly symmetric with respect to the equator. As the Coriolis parameter changes sign across the equator, the mean upwelling changes are of opposite sign north and south of the equator and hence generate almost no upwelling change within the $5^{\circ} \mathrm{S}-5^{\circ} \mathrm{N}$ band.

The mean meridional current changes are southward on both sides of the equator in response to the meridional wind stress changes (Fig. 8b), and they should have opposite contributions to the growth of equatorial SST anomalies that peak at the equator [since $y$ changes sign across the equator in the third term on the right-hand side of (1)]. Therefore, when averaged over the band $5^{\circ} \mathrm{S}-5^{\circ} \mathrm{N}$, the mean meridional advection term (i.e., $\left.V_{\text {damp}}\right)$ does not change much. The mean zonal current dynamical damping contributes little in the control run (Fig. 7a), and the mean zonal current changes again exhibit opposite signs north and south of the equator, yielding only a small $U_{\text {damp }}$ change in Figs. $7 \mathrm{c}$ and $7 \mathrm{~d}$.

\section{d. Changes in positive feedbacks}

Now let us examine the reduction in positive feedbacks in more detail. Because the Ekman feedback contributes little in CESM model (Fig. 7a), we focus on the thermocline feedback and zonal advection feedbacks. We decompose changes in these two feedbacks into their main components (Fig. 9). To the first order, the relative change in each positive feedback (in percent) is equal to the sum of relative changes in its constituting components $[(d z / z) \approx(d x / x)+(d y / y)$ for $z=x y$. 

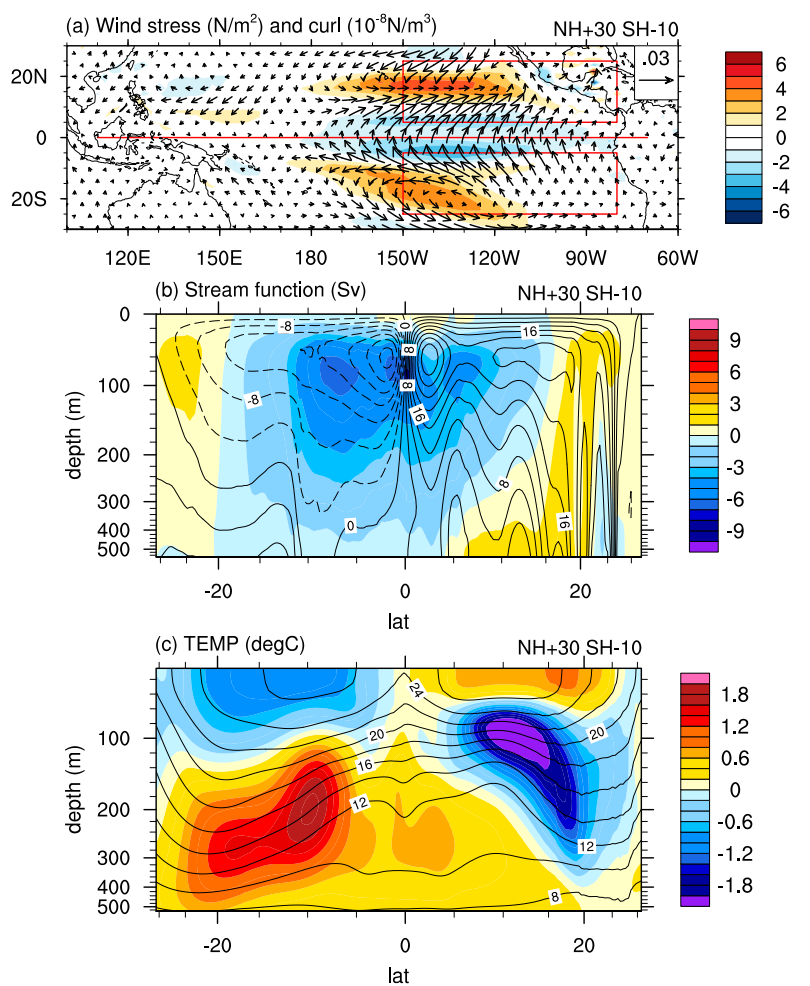

FIG. 8. Induced mean anomalies in (a) mean wind stress (vectors) and wind stress curl (color shading), (b) meridional streamfunction (colors) averaged between $120^{\circ} \mathrm{E}-80^{\circ} \mathrm{W}$, and (c) eastern Pacific subsurface mean temperature (colors) averaged between $150^{\circ}$ $90^{\circ} \mathrm{W}$ in the $\mathrm{NH}+30 / \mathrm{SH}-10$ experiment relative to the control. Contours in (b) and (c) indicate the corresponding climatology from the control run, which shows the Pacific subtropical cells (STCs) and the upper ocean thermocline. Note that the mean equatorial upwelling changes very little. The generally contourclockwise STC response explains the small changes in $W_{\text {damp }}$ and $V_{\text {damp }}$ in Fig. 7c. Similar results can be obtained for the $\mathrm{NH}+40 /$ $\mathrm{SH}-12$ run.

Surprisingly, the atmospheric sensitivity parameter $\mu_{a}$ barely changes even though there is a clear westward shift of wind stress anomalies (not shown), accompanying the westward shift in SST and precipitation anomalies (Fig. 5). On the other hand, changes in $\beta$ coefficients contribute to both positive feedbacks the most. Previous studies using ocean reanalysis products have argued that the shift in ENSO after the year 2000 is associated with a weakening of $\mu_{a}$ (i.e., the sensitivity of zonal wind anomalies to SST anomalies) and $\beta_{h}$ (i.e., the sensitivity of thermochline depth anomalies to zonal wind anomalies) after year 2000 (e.g., Lübbecke and McPhaden 2014), which is different from what we see here. The westward shift of wind stress anomalies could only partially cause the decrease in $\beta_{u}$ (i.e., the sensitivity of zonal current anomalies to zonal wind anomalies) and $\beta_{h}$ by reducing the local component of zonal current anomalies and increasing the propagation distance and hence the damping of Kelvin waves. The weaker stratification, however, is expected to increase $\beta_{h}$ following a simple 1.5-layer shallow-water model argument: the ratio between thermocline depth variations $(\nabla h)$ and sea surface height variations $(\nabla \eta)$ should increase according to the relation $\nabla h=-\left[\rho_{1} /\left(\rho_{2}-\rho_{1}\right)\right] \nabla \eta$, where $h$ and $\eta$ are anomalies in the thermocline depth and sea surface height respectively, and $\rho_{1}$ and $\rho_{2}$ denote the densities of the active upper layer and the motionless deeper layer in the shallow-water model.

Yet, Dewitte (2000) and subsequent studies (e.g., Thual et al. 2013) argue that a weaker stratification could weaken the thermocline feedback through the reduction of the efficiency of mechanical energy transfer from the winds to ocean motion, especially for oceanic baroclinic modes 2 and 3 (i.e., the projection coefficient $P_{n}$ in their studies). This efficiency decrease would affect both our $\beta_{u}$ and $\beta_{h}$ as we define them as regressions of zonal current and thermocline depth anomalies onto wind stress anomalies. The meridional scale and zonal fetch of wind stress anomalies could potentially also influence $\beta_{u}$ and $\beta_{h}$ by influencing this transfer efficiency. Further studies are needed to fully address these questions, which goes beyond the scope of this paper. [See Brown and Fedorov (2010) and Brown et al. (2011) for a detailed discussion of the wind energy transfer efficiency in GCMs which depends on various factors from ocean stratification and thermocline depth to the details of friction parameterization in the models.]

Earlier studies often assert that enhanced upwelling would increase the thermocline positive feedback (e.g., Collins et al. 2010), which is indeed observed in Fig. 9d for our NH-15/SH-5 run. However, $\langle\bar{w}\rangle$ also decides the mean upwelling damping term $\left(W_{\mathrm{damp}} \propto-\langle\bar{w}\rangle\right)$. The net contribution from enhanced upwelling is clearly negative in our NH-15/SH-5 run.

As already mentioned above, changes in the mean ocean temperature field, especially vertical stratification, directly influence positive feedbacks through the terms including $(\partial \bar{T} / \partial x)$ and $a_{h}$ in the Bjerknes index definition [Eq. (1)]; in addition, they can influence the equatorial wave dynamics (and hence $\beta_{u}$ and $\beta_{h}$ ) through the efficiency of wind energy transfer to the thermocline (Dewitte 2000; Brown and Fedorov 2010; Brown et al. 2011). These two terms represent the mean state change, and it is worth looking into the causes of their changes. In the NH-15/SH-5 run the zonal temperature gradient change largely results from the thermocline deepening in the west induced by the enhanced zonal wind stress. The weaker eastern Pacific stratification also results from the equatorial zonal wind change and induces a strong surface cooling (Fig. 4). 
(a) $\mathrm{NH}-15 \mathrm{SH}-5$ minus control

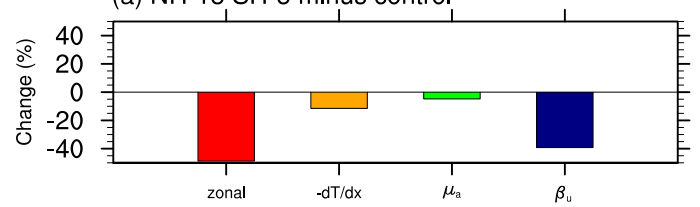

(b) $\mathrm{NH}+30 \mathrm{SH}-10$ minus control

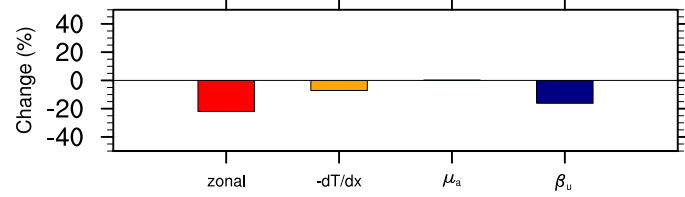

(c) $\mathrm{NH}+40 \mathrm{SH}-12$ minus control

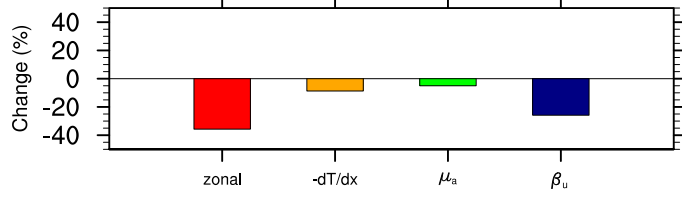

(d) $\mathrm{NH}-15 \mathrm{SH}-5$ minus control

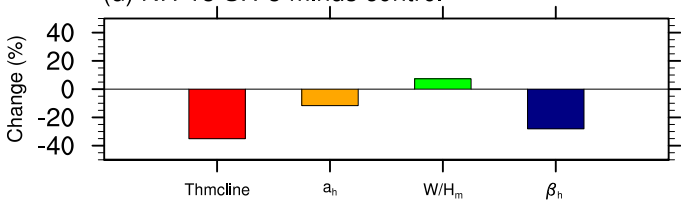

(e) $\mathrm{NH}+30 \mathrm{SH}-10$ minus control

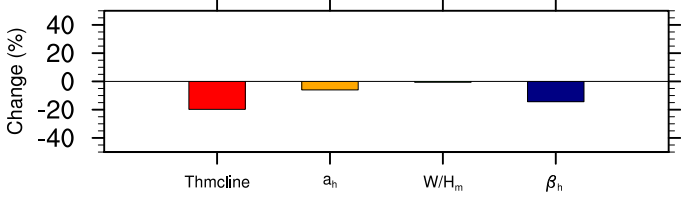

(f) $\mathrm{NH}+40 \mathrm{SH}-12$ minus control

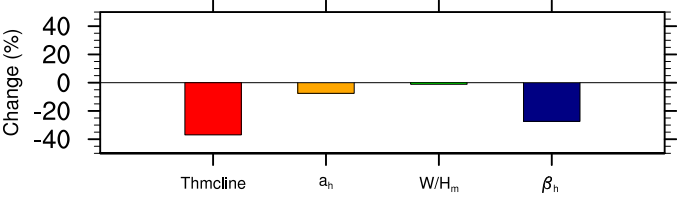

FIG. 9. Decomposing relative changes (in percent) of the two main positive feedbacks into key components. (a)-(c) Decomposition of the zonal advection feedback $\mu_{a} \beta_{u}\langle\partial \bar{T} / \partial x\rangle$. (d)-(f) Decomposition of the thermocline feedback $\mu_{a} \beta_{h} a_{h}\left\langle\bar{w} / H_{m}\right\rangle$. Note that $-\langle\partial \bar{T} / \partial x\rangle$ is shown in (a)-(c).

In the two meridional wind experiments, the zonal and vertical temperature gradient change might be due in part to the residual zonal wind stress as commented above. However, a better understanding could be gained if we examine an eastern Pacific meridional section (Fig. 8c, here an average between $150^{\circ}-90^{\circ} \mathrm{W}$ is used). The mean temperature change along this section exhibits a quadrupole pattern with cooling south of the equator and warming north of the equator near the ocean surface, but an opposite pattern at around the depth of the thermocline. Apparently, the near-surface temperature changes arise as a direct response to the induced wind stress changes and heat flux forcing: cooling south of the equator is due to the intensified winds and imposed negative heat flux, while the opposite is true north of the equator. The temperature changes at depth are dynamically consistent with the induced mean anomalies in wind stress curl (Fig. 8a) and the subtropical cells (Fig. 8b): a positive change in wind stress curl induces downwelling (upwelling) anomalies south (north) of the equator and hence positive (negative) mean temperature anomalies around the thermocline.

Note however that the quadrupole pattern is not perfectly symmetric: the temperature anomaly north of the equator is shallower than that south of the equator. Recall that temperature anomalies resulting from anomalous upwelling/downwelling should be located around the depth of mean vertical temperature gradient maximum (i.e., the thermocline). Therefore, the temperature anomalies being shallower north of the equator is a result of the mean thermocline being shallower there, which in turn results from a large climatological wind stress curl (and mean upwelling) associated with the ITCZ. When averaged over the equatorial band $\left(5^{\circ} \mathrm{S}-5^{\circ} \mathrm{N}\right)$, this asymmetry in the mean temperature change yields the cold core right above the thermocline in the eastern equatorial Pacific seen in Fig. 4. On the other hand, as the mean temperature field is quite symmetric with respect to the equator in the western Pacific, temperature anomalies there have similar depth (not shown), which explains why the cold mean temperature anomalies are confined to the eastern Pacific.

In short, the asymmetry in mean temperature changes in response to the imposed forcing is due to the spatial asymmetry in the climatological temperature field associated with the northerly mean position of the ITCZ. Another factor contributing to the weakened stratification in the eastern equatorial Pacific (Fig. 4) is a significant warming below the thermocline (Fig. 8c). We do not have a clear explanation for this broad warming but suspect that it might be due to the advection by the mean Equatorial Undercurrent of positive temperature anomalies that originated south of the equator.

To summarize, our analysis suggests that the weakening of the oceanic sensitivity parameters contributes most to the ENSO cycle shift in all of our perturbed runs, in part consistent with what was found for the ocean reanalysis products (Lübbecke and McPhaden 2014). However, the strengthening of the zonal temperature gradient and the weakening of the ocean stratification in the eastern equatorial Pacific might be what initiates the weakening of the advection and 
(a) control

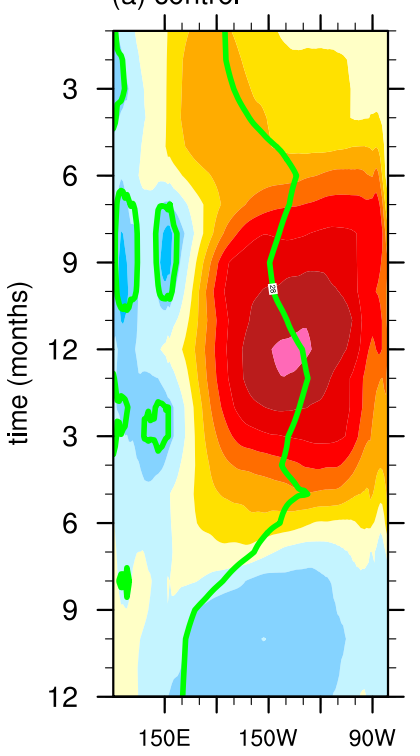

(b) $\mathrm{NH}-15 \mathrm{SH}-5$

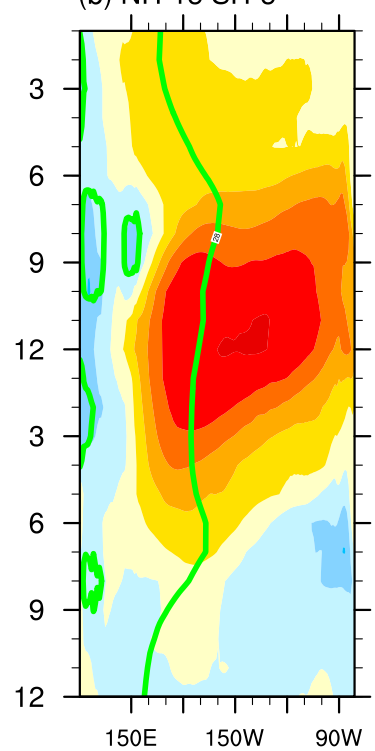

(c) $\mathrm{NH}+30 \mathrm{SH}-10$

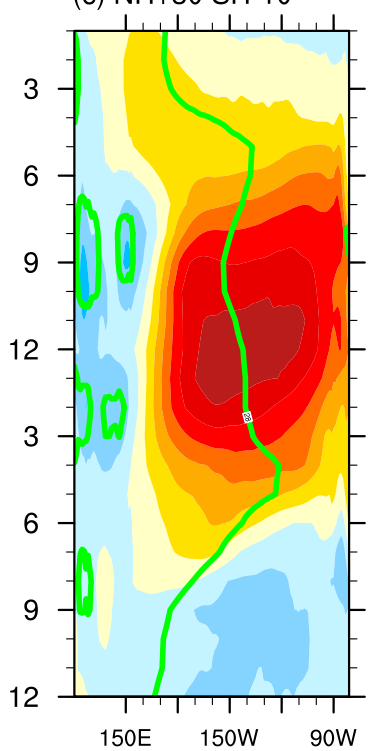

(d) $\mathrm{NH}+40 \mathrm{SH}-12$

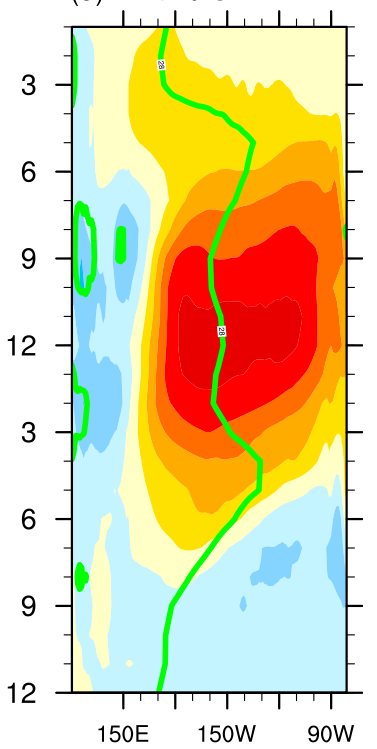

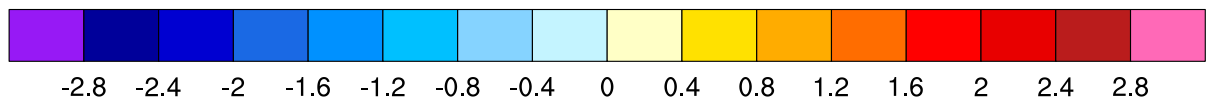

FIG. 10. Hovmöller diagrams showing SST anomalies (in ${ }^{\circ} \mathrm{C}$ ) of El Niño composites for (a) the control run and (b)-(d) the perturbed runs. Green contours denote $28^{\circ} \mathrm{C}$ isotherms (the warm pool eastern edge). Time runs from top to bottom $(1=\mathrm{January} ; 12=\mathrm{December})$. Note the stronger El Niño amplitude, greater eastward expansion of the warm pool during the event peaks, and subtle differences in the direction of anomaly propagation in the control run as compared to the perturbation experiments.

thermocline feedbacks and finally leads to the westward shift of the ENSO-related SST/wind stress/precipitation anomalies. (As part of the changes, the ITCZ is forced to stay north of the equator.) The cause of the $(\partial \bar{T} / \partial x)$ and $a_{h}$ change is thermocline steepening and surface cooling in the NH-15/SH-5 run but is more complicated in the $\mathrm{NH}+30 / \mathrm{SH}-10$ and $\mathrm{NH}+40 / \mathrm{SH}-12$ runs.

\section{Discussion and conclusions}

By imposing surface anomalous heat fluxes in targeted regions in the tropical/subtropical Pacific, we are able to alter (separately) mean equatorial zonal winds and cross-equatorial meridional winds in a comprehensive coupled GCM (CESM). When negative heat fluxes are imposed on both sides of the equator (the NH-15/SH-5 experiment), only the mean equatorial zonal wind strengthens. When heat fluxes of opposite signs are imposed, only the cross-equatorial wind strengthens. It is shown that the ENSO cycle exhibits qualitatively similar changes for both types of perturbations to the mean state, reducing El Niño amplitude, and affecting the location of maximum SST anomalies and the ITCZ behavior; although in our experiments the zonal wind effect is generally stronger than the meridional wind effect, given comparable magnitudes of the imposed wind changes. Some of the effects of such wind changes on ENSO are highlighted by the resulting differences in the typical evolution of El Niño events (Fig. 10), including a weaker El Niño amplitude, smaller eastward expansion of the warm pool during the peak of the events, and subtle differences in the direction of anomaly propagation in the perturbed experiments relative to the control.

Weaker eastern Pacific SST El Niño anomalies in both types of experiments are accounted for by the weakening of the positive Bjerknes feedback, which in turn results largely from the weakening of oceanic sensitivities to wind stress. The westward shift of wind stress anomalies partially explains the reduction in $\beta_{u}$ (the zonal current sensitivity) and $\beta_{h}$ (the thermocline depth sensitivity). The weaker stratification, however, can explain the decrease in $\beta_{h}$ only if we invoke the argument of wind energy transfer to higher baroclinic modes (modes 2 and 3), which is not included in the 1.5-layer shallowwater model. Other factors such as the meridional scale and zonal fetch of wind stress anomalies might also contribute to the decrease in $\beta_{h}$.

Ultimately, this study implies that the observed zonal winds strengthening over the past three decades, 
together with the meridional trade wind strengthening, could have contributed to the documented shift in ENSO cycle and the diversity of El Niño events after the year 2000. Likewise, the weakening of those winds may have been responsible for the ENSO shift of the late 1970s. Comparing the magnitudes of the imposed wind changes with the observations of the past several decades suggests that a larger contribution to the observed ENSO cycle change may have come from the zonal wind strengthening and a smaller, albeit important, part from the meridional wind strengthening. Quantifying the exact ratio of the two effects is difficult because different periods of observations and different datasets give different values of cross-equatorial wind increase [see supplementary Fig. 2 of $\mathrm{Hu}$ and Fedorov (2018)] and because model biases result in too weak background cross-equatorial winds. Thus, changes in both wind components should be monitored to understand and anticipate decadal modulations in ENSO, especially if cross-equatorial winds continue to strengthen with global warming. Debates continue on whether the observed modulations in ENSO result from internal variability of the tropical ocean-atmosphere system, are externally forced through changes in the mean state of the tropical Pacific, or just happen at random. At the very least, this study demonstrates that changes in mean zonal and meridional winds of realistic magnitudes can lead to ENSO changes comparable to the observed.

It is noteworthy that the mean state changes in the two meridional wind experiments are qualitatively similar, but have an opposite sign, to changes induced in the Pacific Ocean within hosing experiments causing the collapse of the Atlantic meridional overturning circulation (e.g., Zhang and Delworth 2005; Dong and Sutton 2007; Timmermann et al. 2007). In those experiments weakened cross-equatorial winds corresponded to a stronger ENSO, whereas in our experiments enhanced cross-equatorial winds correspond to a weaker ENSO. This is also consistent with the idea of a remote Atlantic forcing causing the observed ENSO cycle shift (Hu and Fedorov 2018; Levine et al. 2017; Kang et al. 2014; Williamson et al. 2018; Zanchettin et al. 2016).

Our findings are also relevant to the topic of ENSO future response to global warming, which remains hotly debated in view of the delicate balance among various amplifying and damping feedbacks (e.g., Collins et al. 2010; DiNezio et al. 2012; Stevenson 2012; Capotondi et al. 2015) and the difficulty of separating forced ENSO changes from internal changes (Wittenberg 2009; Wittenberg et al. 2014). As climate response to anthropogenic global warming is expected to be somewhat different in the two hemispheres, with the $\mathrm{NH}$ warming faster than the SH (Flato and Boer 2001; Xie et al. 2010), the resulting enhanced north-south asymmetry could induce a stronger background meridional wind, leading to a weaker ENSO cycle and more frequency CP events. However, an enhanced eastern equatorial warming pattern, seen in GCM greenhouse-warming simulations (Knutson and Manabe 1995; Meehl et al. 2000; Liu et al. 2005; DiNezio et al. 2009; Xie et al. 2010), may counteract the cross-equatorial wind response. In fact, there is no agreement across the models on the future changes in cross-equatorial winds (Hu and Fedorov 2018). At the same time, the anticipated eventual weakening of the Walker circulation and trade winds (e.g., Vecchi and Soden 2007; DiNezio et al. 2009) may change the ENSO cycle in the opposite direction with an uncertain net result.

Another important issue complicating future ENSO projections is related to persistent model biases. As mentioned earlier, GCMs tend to overestimate the equatorial easterly winds (Bellenger et al. 2014; Burls et al. 2017) while underestimating the cross-equatorial southerly winds (Hu and Fedorov 2018), which results in the equatorial cold tongue penetrating too far west and in the mean state being too symmetric with respect to the equator. While these two GCM biases may partially cancel the effects of each other on ENSO simulations, the resultant error compensation may distort the physics of both present and future El Niño. Eliminating such model biases will be necessary to improve our confidence in climate projections.

Acknowledgments. This research was supported by grants to A.V.F. from the NSF (AGS- 0163807), NOAA (NA14OAR4310277), and NASA (NNX17AH21G). B.Z. was supported by a NASA Earth and Space Sciences Graduate Fellowship. We also acknowledge computational support from the Yale University Faculty of Arts and Sciences High Performance Computing facility, from the NSF/NCAR Yellowstone Supercomputing Center, and from the NASA High-End Computing Program.

\section{REFERENCES}

Ashok, K., and T. Yamagata, 2009: Climate change: The El Niño with a difference. Nature, 461, 481-484, https://doi.org/10. 1038/461481a.

_ S. K. Behera, S. A. Rao, H. Weng, and T. Yamagata, 2007: El Niño Modoki and its possible teleconnection. J. Geophys. Res, 112, C11007, https://doi.org/10.1029/2006JC003798.

Battisti, D. S., and A. C. Hirst, 1989: Interannual variability in a tropical atmosphere-ocean model: Influence of the basic state, ocean geometry and nonlinearity. J. Atmos. Sci., 46, 1687-1712, https:// doi.org/10.1175/1520-0469(1989)046<1687:IVIATA>2.0.CO;2.

Bejarano, L., and F.-F. Jin, 2008: Coexistence of equatorial coupled modes of ENSO. J. Climate, 21, 3051-3067, https://doi.org/ 10.1175/2007JCLI1679.1. 
Bellenger, H., É. Guilyardi, J. Leloup, M. Lengaigne, and J. Vialard, 2014: ENSO representation in climate models: From CMIP3 to CMIP5. Climate Dyn., 42, 1999-2018, https://doi.org/10.1007/s00382-013-1783-z.

Brown, J. N., and A. V. Fedorov, 2010: How much energy is transferred from the winds to the thermocline on ENSO time scales? J. Climate, 23, 1563-1580, https://doi.org/10.1175/ 2009JCLI2914.1.

$\_, \ldots$, and E. Guilyardi, 2011: How well do coupled models replicate ocean energetics relevant to ENSO? Climate Dyn., 36, 2147-2158, https://doi.org/10.1007/s00382-010-0926-8.

Burls, N., and A. Fedorov, 2014: What controls the mean east-west sea surface temperature gradient in the equatorial Pacific: The role of cloud albedo. J. Climate, 27, 2757-2778, https://doi.org/ 10.1175/JCLI-D-13-00255.1.

— L. Luir, E. M. Vincent, and A. Fedorov, 2017: Extra-tropical origin of equatorial Pacific cold bias in climate models with links to cloud albedo. Climate Dyn., 49, 2093-2113, https:// doi.org/10.1007/s00382-016-3435-6.

Cai, W., and Coauthors, 2015: ENSO and greenhouse warming. Nat. Climate Change, 5, 849-859, https://doi.org/10.1038/ nclimate2743.

Capotondi, A., and Coauthors, 2015: Understanding ENSO diversity. Bull. Amer. Meteor. Soc., 96, 921-938, https://doi.org/ 10.1175/BAMS-D-13-00117.1.

Chang, P., L. Zhang, R. Saravanan, D. J. Vimont, J. C. Chiang, L. Ji, H. Seidel, and M. K. Tippett, 2007: Pacific meridional mode and El Niño-Southern Oscillation. Geophys. Res. Lett., 34, L16608, https://doi.org/10.1029/2007GL030302.

Clarke, A. J., 2008: An Introduction to the Dynamics of El Niño and the Southern Oscillation. Elsevier, 324 pp.

Collins, M., and Coauthors, 2010: The impact of global warming on the tropical Pacific Ocean and El Niño. Nat. Geosci., 3, 391397, https://doi.org/10.1038/ngeo868.

Dewitte, B., 2000: Sensitivity of an intermediate ocean-atmosphere coupled model of the tropical Pacific to its oceanic vertical structure. J. Climate, 13, 2363-2388, https://doi.org/10.1175/ 1520-0442(2000)013<2363:SOAIOA > 2.0.CO;2.

Di Lorenzo, E., G. Liguori, N. Schneider, J. Furtado, B. Anderson, and M. Alexander, 2015: ENSO and meridional modes: A null hypothesis for Pacific climate variability. Geophys. Res. Lett., 42, 9440-9448, https://doi.org/10.1002/2015GL066281.

DiNezio, P. N., A. C. Clement, G. A. Vecchi, B. J. Soden, B. P. Kirtman, and S.-K. Lee, 2009: Climate response of the equatorial Pacific to global warming. J. Climate, 22, 4873-4892, https://doi.org/10.1175/2009JCLI2982.1.

- B. P. Kirtman, A. C. Clement, S.-K. Lee, G. A. Vecchi, and A. Wittenberg, 2012: Mean climate controls on the simulated response of ENSO to increasing greenhouse gases. J. Climate, 25, 7399-7420, https://doi.org/10.1175/JCLI-D-11-00494.1.

Dong, B., and R. T. Sutton, 2007: Enhancement of ENSO variability by a weakened Atlantic thermohaline circulation in a coupled GCM. J. Climate, 20, 4920-4939, https://doi.org/10.1175/JCLI4284.1.

,-- , and A. A. Scaife, 2006: Multidecadal modulation of El Niño-Southern Oscillation (ENSO) variance by Atlantic Ocean sea surface temperatures. Geophys. Res. Lett., 33, L08705, https://doi.org/10.1029/2006GL025766.

England, M. H., and Coauthors, 2014: Recent intensification of wind-driven circulation in the Pacific and the ongoing warming hiatus. Nat. Climate Change, 4, 222-227, https://doi.org/ 10.1038/nclimate2106.

Fedorov, A. V., 2010: Ocean response to wind variations, warm water volume, and simple models of ENSO in the low-frequency approximation. J. Climate, 23, 3855-3873, https://doi.org/ 10.1175/2010JCLI3044.1.

- and S. G. Philander, 2000: Is El Niño changing? Science, 288, 1997-2002, https://doi.org/10.1126/science.288.5473.1997.

, and —, 2001: A stability analysis of tropical oceanatmosphere interactions: Bridging measurements and theory for El Niño. J. Climate, 14, 3086-3101, https://doi.org/10.1175/ 1520-0442(2001)014<3086:ASAOTO > 2.0.CO;2.

— Ocean Sciences, J. Steele, Ed., Academic Press, 3679-3695, https://people.earth.yale.edu/sites/default/files/files/Fedorov/ 50_Fedorov_EqWaves_Encyclopedia_2009.pdf.

- S. Harper, S. Philander, B. Winter, and A. Wittenberg, 2003: How predictable is El Niño? Bull. Amer. Meteor. Soc., 84, 911920, https://doi.org/10.1175/BAMS-84-7-911.

_, S. Hu, M. Lengaigne, and E. Guilyardi, 2015: The impact of westerly wind bursts and ocean initial state on the development and diversity of El Niño events. Climate Dyn., 44, 13811401, https://doi.org/10.1007/s00382-014-2126-4.

Flato, G., and G. Boer, 2001: Warming asymmetry in climate change simulations. Geophys. Res. Lett., 28, 195-198, https:// doi.org/10.1029/2000GL012121.

Gill, A. E., 1980: Some simple solutions for heat-induced tropical circulation. Quart. J. Roy. Meteor. Soc., 106, 447-462, https:// doi.org/10.1002/qj.49710644905.

Guilyardi, E., 2006: El Niño-mean state-seasonal cycle interactions in a multi-model ensemble. Climate Dyn., 26, 329-348, https://doi.org/10.1007/s00382-005-0084-6.

— , P. Braconnot, F.-F. Jin, S. T. Kim, M. Kolasinski, T. Li, and I. Musat, 2009: Atmosphere feedbacks during ENSO in a coupled GCM with a modified atmospheric convection scheme. J. Climate, 22, 5698-5718, https://doi.org/10.1175/2009JCLI2815.1.

, H. Bellenger, M. Collins, S. Ferrett, W. Cai, and A. Wittenberg, 2012: A first look at ENSO in CMIP5. CLIVAR Exchanges, No. 17, International CLIVAR Project Office, Southampton, United Kingdom, 29-32, https://folk.uib.no/ngfhd/EarthClim/ Publications/Papers/Guilyardi_etal_2012.pdf.

He, J., and B. J. Soden, 2015: Anthropogenic weakening of the tropical circulation: The relative roles of direct $\mathrm{CO}_{2}$ forcing and sea surface temperature change. J. Climate, 28, 8728-8742, https://doi.org/10.1175/JCLI-D-15-0205.1.

Hu, S., and A. V. Fedorov, 2016: Exceptionally strong easterly wind burst stalling El Niño of 2014. Proc. Natl. Acad. Sci. USA, 113, 2005-2010, https://doi.org/10.1073/pnas.1514182113.

_ , and _ 2017: The extreme El Niño of 2015-2016: The role of westerly and easterly wind bursts, and preconditioning by the failed 2014 event. Climate Dyn., 52, 7339-7357, https:// doi.org/10.1007/S00382-017-3531-2.

$\longrightarrow$, and - 2018: Cross-equatorial winds control El Niño diversity and change. Nat. Climate Change, 8, 798-802, https:// doi.org/10.1038/s41558-018-0248-0.

Hu, Z.-Z., A. Kumar, H.-L. Ren, H. Wang, M. L'Heureux, and F.-F. Jin, 2013: Weakened interannual variability in the tropical Pacific Ocean since 2000. J. Climate, 26, 2601-2613, https:// doi.org/10.1175/JCLI-D-12-00265.1.

- _ - and B. Huang, 2016: Spatial distribution and the interdecadal change of leading modes of heat budget of the mixed-layer in the tropical Pacific and the association with ENSO. Climate Dyn., 46, 1753-1768, https://doi.org/10.1007/ s00382-015-2672-4.

,,,--- J. Zhu, and H.-L. Ren, 2017: Interdecadal variations of ENSO around 1999/2000. J. Meteor. Res., 31, 73-81, https://doi.org/10.1007/s13351-017-6074-x. 
Hurrell, J. W., and Coauthors, 2013: The Community Earth System Model: A framework for collaborative research. Bull. Amer. Meteor. Soc., 94, 1339-1360, https://doi.org/10.1175/BAMS-D12-00121.1.

Jin, F.-F., 1997: An equatorial ocean recharge paradigm for ENSO. Part I: Conceptual model. J. Atmos. Sci., 54, 811-829, https:// doi.org/10.1175/1520-0469(1997)054<0811:AEORPF>2.0.CO;2.

_, S. T. Kim, and L. Bejarano, 2006: A coupled-stability index for ENSO. Geophys. Res. Lett., 33, L23708, https://doi.org/ 10.1029/2006GL027221.

Kang, I.-S., H. No, and F. Kucharski, 2014: ENSO amplitude modulation associated with the mean SST changes in the tropical central Pacific induced by Atlantic multidecadal oscillation. J. Climate, 27, 7911-7920, https://doi.org/10.1175/ JCLI-D-14-00018.1.

Kim, H.-M., P. J. Webster, and J. A. Curry, 2011: Modulation of North Pacific tropical cyclone activity by three phases of ENSO. J. Climate, 24, 1839-1849, https://doi.org/10.1175/ 2010JCLI3939.1.

Kim, S. T., and F.-F. Jin, 2011a: An ENSO stability analysis. Part I: Results from a hybrid coupled model. Climate Dyn., 36, 15931607, https://doi.org/10.1007/s00382-010-0796-0.

$\longrightarrow$, and _ 2011b: An ENSO stability analysis. Part II: Results from the twentieth and twenty-first century simulations of the CMIP3 models. Climate Dyn., 36, 1609-1627, https://doi.org/ 10.1007/s00382-010-0872-5.

—, and J.-Y. Yu, 2012: The two types of ENSO in CMIP5 models. Geophys. Res. Lett., 39, L11704, https://doi.org/10. 1029/2012GL052006.

Knutson, T. R., and S. Manabe, 1995: Time-mean response over the tropical Pacific to increased $\mathrm{CO}_{2}$ in a coupled ocean-atmosphere model. J. Climate, 8, 2181-2199, https://doi.org/10.1175/15200442(1995)008<2181:TMROTT > 2.0.CO;2.

Kug, J.-S., F.-F. Jin, and S.-I. An, 2009: Two types of El Niño events: Cold tongue El Niño and warm pool El Niño. J. Climate, 22, 1499-1515, https://doi.org/10.1175/2008JCLI2624.1.

—, J. Choi, S.-I. An, F.-F. Jin, and A. T. Wittenberg, 2010: Warm pool and cold tongue El Niño events as simulated by the GFDL 2.1 coupled GCM. J. Climate, 23, 1226-1239, https:// doi.org/10.1175/2009JCLI3293.1.

Lee, T., and M. J. McPhaden, 2010: Increasing intensity of El Niño in the central-equatorial Pacific. Geophys. Res. Lett., 37, L14603, https://doi.org/10.1029/2010GL044007.

Levine, A. F., M. J. McPhaden, and D. M. Frierson, 2017: The impact of the AMO on multidecadal ENSO variability. Geophys. Res. Lett., 44, 3877-3886, https://doi.org/10.1002/ 2017 GL072524.

Li, G., and S.-P. Xie, 2014: Tropical biases in CMIP5 multimodel ensemble: The excessive equatorial Pacific cold tongue and double ITCZ problems. J. Climate, 27, 1765-1780, https:// doi.org/10.1175/JCLI-D-13-00337.1.

Li, W., P. Zhang, J. Ye, L. Li, and P. A. Baker, 2011: Impact of two different types of El Niño events on the Amazon climate and ecosystem productivity. J. Plant Ecol., 4, 91-99, https://doi.org/ 10.1093/jpe/rtq039.

Liu, Z., and B. Huang, 1997: A coupled theory of tropical climatology: Warm pool, cold tongue, and Walker circulation. J. Climate, 10, 1662-1679, https://doi.org/10.1175/ 1520-0442(1997)010<1662:ACTOTC>2.0.CO;2.

, S. Vavrus, F. He, N. Wen, and Y. Zhong, 2005: Rethinking tropical ocean response to global warming: The enhanced equatorial warming. J. Climate, 18, 4684-4700, https://doi.org/ 10.1175/JCLI3579.1.
Lübbecke, J. F., and M. J. McPhaden, 2013: A comparative stability analysis of Atlantic and Pacific Niño modes. J. Climate, 26, 5965-5980, https://doi.org/10.1175/JCLI-D-12-00758.1.

$\longrightarrow$, and - 2014: Assessing the twenty-first-century shift in ENSO variability in terms of the Bjerknes stability index. J. Climate, 27, 2577-2587, https://doi.org/10.1175/JCLI-D-1300438.1.

Manucharyan, G. E., and A. V. Fedorov, 2014: Robust ENSO across a wide range of climates. J. Climate, 27, 5836-5850, https://doi.org/10.1175/JCLI-D-13-00759.1.

McPhaden, M., 2012: A 21st century shift in the relationship between ENSO SST and warm water volume anomalies. Geophys. Res. Lett., 39, L09706, https://doi.org/10.1029/ 2012GL051826.

- 2015: Playing hide and seek with El Niño. Nat. Climate Change, 5, 791-795, https://doi.org/10.1038/nclimate2775.

— T. Lee, and D. McClurg, 2011: El Niño and its relationship to changing background conditions in the tropical Pacific Ocean. Geophys. Res. Lett., 38, L15709, https://doi.org/10.1029/ 2011 GL048275.

Meehl, G. A., W. D. Collins, B. A. Boville, J. T. Kiehl, T. Wigley, and J. M. Arblaster, 2000: Response of the NCAR Climate System Model to increased $\mathrm{CO}_{2}$ and the role of physical processes. J. Climate, 13, 1879-1898, https://doi.org/10.1175/ 1520-0442(2000)013<1879:ROTNCS > 2.0.CO;2.

Meinen, C. S., and M. J. McPhaden, 2000: Observations of warm water volume changes in the equatorial Pacific and their relationship to El Niño and La Niña. J. Climate, 13, 3551-3559, https://doi.org/10.1175/1520-0442(2000)013<3551:OOWWVC> 2.0.CO;2.

Min, Q., J. Su, R. Zhang, and X. Rong, 2015: What hindered the El Niño pattern in 2014? Geophys. Res. Lett., 42, 6762-6770, https://doi.org/10.1002/2015GL064899.

Philander, S., 1990: E1 Niño, La Niña, and the Southern Oscillation. Academic Press, 293 pp.

Ren, H.-L., and F.-F. Jin, 2013: Recharge oscillator mechanisms in two types of ENSO. J. Climate, 26, 6506-6523, https://doi.org/ 10.1175/JCLI-D-12-00601.1.

Sarachik, E. S., and M. A. Cane, 2010: The El Niño-Southern Oscillation Phenomenon. Cambridge University Press, 384 pp.

Stevenson, S., 2012: Significant changes to ENSO strength and impacts in the twenty-first century: Results from CMIP5. Geophys. Res. Lett., 39, L17703, https://doi.org/10.1029/ 2012GL052759.

Thual, S., B. Dewitte, S.-I. An, S. Illig, and N. Ayoub, 2013: Influence of recent stratification changes on ENSO stability in a conceptual model of the equatorial Pacific. J. Climate, 26, 4790-4802, https://doi.org/10.1175/JCLI-D-12-00363.1.

Timmermann, A., and Coauthors, 2007: The influence of a weakening of the Atlantic meridional overturning circulation on ENSO. J. Climate, 20, 4899-4919, https://doi.org/10.1175/ JCLI4283.1.

_- and Coauthors, 2018: El Niño-Southern Oscillation complexity. Nature, 559, 535-545, https://doi.org/10.1038/s41586018-0252-6.

Vecchi, G. A., and B. J. Soden, 2007: Global warming and the weakening of the tropical circulation. J. Climate, 20, 43164340, https://doi.org/10.1175/JCLI4258.1.

Wang, B., and S. An, 2002: A mechanism for decadal changes of ENSO behavior: Roles of background wind changes. Climate Dyn., 18, 475-486, https://doi.org/10.1007/s00382-001-0189-5.

Wang, C., C. Deser, J.-Y. Yu, P. DiNezio, and A. Clement, 2017: El Niño and Southern Oscillation (ENSO): A review. Coral Reefs 
of the Eastern Tropical Pacific, P. W. Glynn, D. P. Manzello, and I. C. Enochs, Eds., Springer, 85-106.

Williamson, M. S., M. Collins, S. S. Drijfhout, R. Kahana, J. V. Mecking, and T. M. Lenton, 2018: Effect of AMOC collapse on ENSO in a high resolution general circulation model. Climate Dyn., 50, 2537-2552, https://doi.org/10.1007/s00382017-3756-0.

Wittenberg, A. T., 2009: Are historical records sufficient to constrain ENSO simulations? Geophys. Res. Lett., 36, L12702, https://doi.org/10.1029/2009GL038710.

- A. Rosati, T. L. Delworth, G. A. Vecchi, and F. Zeng, 2014: ENSO modulation: Is it decadally predictable? J. Climate, 27, 2667-2681, https://doi.org/10.1175/JCLI-D-13-00577.1.

Wu, Y.-K., L. Chen, C.-C. Hong, T. Li, C.-T. Chen, and L. Wang, 2018: Role of the meridional dipole of SSTA and associated cross-equatorial flow in the tropical eastern Pacific in terminating the 2014 El Niño development. Climate Dyn., 50, 16251638, https://doi.org/10.1007/s00382-017-3710-1.

Xie, R., and F.-F. Jin, 2018: Two leading ENSO modes and El Niño types in the Zebiak-Cane model. J. Climate, 31, 1943-1962, https://doi.org/10.1175/JCLI-D-17-0469.1.

Xie, S.-P., C. Deser, G. A. Vecchi, J. Ma, H. Teng, and A. T. Wittenberg, 2010: Global warming pattern formation: Sea surface temperature and rainfall. J. Climate, 23, 966-986, https://doi.org/10.1175/2009JCLI3329.1.

Yeh, S.-W., J.-S. Kug, B. Dewitte, M.-H. Kwon, B. P. Kirtman, and F.-F. Jin, 2009: El Niño in a changing climate. Nature, 461, 511-514, https://doi.org/10.1038/nature08316.

Zanchettin, D., O. Bothe, H. F. Graf, N.-E. Omrani, A. Rubino, and J. H. Jungclaus, 2016: A decadally delayed response of the tropical Pacific to Atlantic multidecadal variability. Geophys. Res. Lett., 43, 784-792, https://doi.org/10.1002/2015GL067284.

Zebiak, S. E., and M. A. Cane, 1987: A model El Niño-Southern Oscillation. Mon. Wea. Rev., 115, 2262-2278, https://doi.org/ 10.1175/1520-0493(1987)115<2262:AMENO>2.0.CO;2.

Zhang, H., C. Deser, A. Clement, and R. Tomas, 2014: Equatorial signatures of the Pacific meridional modes: Dependence on mean climate state. Geophys. Res. Lett., 41, 568-574, https:// doi.org/10.1002/2013GL058842.

Zhang, R., and T. L. Delworth, 2005: Simulated tropical response to a substantial weakening of the Atlantic thermohaline circulation. J. Climate, 18, 1853-1860, https://doi.org/10.1175/JCLI3460.1.

Zhu, J., A. Kumar, B. Huang, M. A. Balmaseda, Z.-Z. Hu, L. Marx, and J. L. Kinter III, 2016: The role of off-equatorial surface temperature anomalies in the 2014 El Niño prediction. Sci. Rep., 6, 19677, https://doi.org/10.1038/srep19677. 